\title{
Heat transfer and recovery performance enhancement of metal and superconducting tapes under high current pulses for improving fault current limiting behavior of HTS transformers
}

\author{
Mohammad Yazdani-Asrami ${ }^{\mathrm{a}, \mathrm{b}} *$ Mike Staines $^{\mathrm{a}}$, Gennady Sidorov ${ }^{\mathrm{a}}$, and Alain Eicher ${ }^{\mathrm{a}, \mathrm{c}}$ \\ ${ }^{\text {a }}$ Robinson Research Institute, Victoria University of Wellington, Wellington, New Zealand

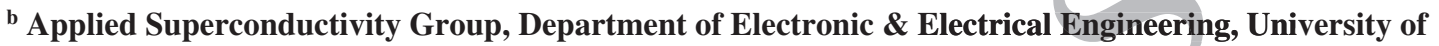 \\ Strathclyde, Glasgow, United Kingdom \\ ${ }^{c}$ Department of Electrical Engineering and Information Technology, Karlsruhe Institute of Technology,
} Karlsruhe, Germany

\begin{abstract}
:
High temperature superconducting (HTS) transformers windings operate subcooled at atmospheric pressure to temperatures as low as $65 \mathrm{~K}$, with minimal power dissipation from AC loss in normal operation. During short circuits, HTS transformers are subjected to transient heating by currents as much as 10x rated current for durations of up to $2 \mathrm{~s}$. After isolating the fault, HTS transformers are required to cool back down to their base temperature while carrying the operating current. HTS transformer conductors are insulated, typically with wrapped self-adhesive polyimide tape, and windings consist of close packed conductors wound on composite formers.

In this paper, the heat transfer, transient thermal response, and recovery performance of brass-laminated coated conductor HTS wire as well as metallic conductors in liquid nitrogen (LN2) were measured at a range of temperatures from $77 \mathrm{~K}$ to $64 \mathrm{~K}$ and pressures from atmospheric to 0.14 bar in heating and cooling situations. Measurements were made on bare tapes, and on tapes wrapped with polyimide insulation tape and with aramid paper as well as polymer coated tapes with a range of coating thickness. Heat transfer from tapes mounted with one face in contact with a glass-epoxy composite cylindrical former was measured for comparison with free-standing tapes. Using conductors with solid polymer coatings of optimized thickness immersed in subcooled LN2 results in the highest heat transfer and fast recovery following heating to $300 \mathrm{~K}$ by a high current pulse. Compared to a bare tape in LN2 at ambient pressure at $77 \mathrm{~K}$, the heat transfer in a coated tape in $65 \mathrm{~K}$ subcooled LN2 can be very significantly enhanced, by up to a factor of 15x, and recovery can be 7x faster.
\end{abstract}

Keywords: Fault performance, Heat Transfer, High Temperature Superconductors, Liquid Nitrogen, Recovery Time, Solid Coating, Short circuit current, Subcooling, Superconducting transformer, Superconducting Fault Current limiter.

\section{Introduction}

Power transformers are required to withstand the fault current for up to $2 \mathrm{~s}$ stipulated in IEC test standards ${ }^{1}$ and required by network operators to continue to carry current during a fault to allow time for protection systems to isolate only the faulty section of the power network. A further requirement is the need to continue to operate at rated current after the fault is isolated. For large conventional power transformers, with relatively massive copper or aluminium conductors operating at rated current densities of around 3 to $5 \mathrm{~A} / \mathrm{mm} 2$, and fault currents up to 10x higher, these requirements are routinely met. For high temperature superconducting (HTS) conductors of superconducting transformers, with much higher current densities and lower thermal mass, these requirements are extremely challenging. In contrast, resistive 
superconducting fault current limiters ${ }^{2}$ (SFCLs) are typically isolated from the fault current within 5 to 10 cycles, and recover while disconnected, so heat transfer is not a primary concern, and thus, the design assumes adiabatic heating during the fault, i.e. ignoring any heat transfer. Therefore, heat transfer in liquid nitrogen (LN2) is critically important in the design of HTS transformers. Heat transfer by natural convection and pool boiling affect transformer performance both in normal operation, where natural convection limits the temperature rise produced by $\mathrm{AC}$ loss ${ }^{3}$ in the HTS windings, but also during a fault current event and subsequent recovery, where maximizing the boiling heat transfer is a crucial design objective if HTS transformers are to perform to the standards required by power networks.

Most of the literature work on heat transfer in LN2 are in equilibrium conditions. Heat transfer shows a progressive transition with increasing heat flux from natural convection to nucleate boiling to film boiling ${ }^{4}$. Transient heat transfer, with rapidly increasing heat flux, has been shown to produce a transition to film boiling at lower heat flux than in equilibrium conditions ${ }^{5}$. Surface roughness has a major influence on nucleate boiling, with rough surfaces exhibiting higher heat flux at lower surface temperature than smooth surfaces ${ }^{6}$. Surface orientation also has an effect ${ }^{7}$.

Insulating coatings can significantly improve boiling transfer ${ }^{8,9}$. The effect has been known for over 50 years ${ }^{10}$, and was patented in $1969^{11}$. A coating with appropriate thermal resistance keeps the surface cold enough to avoid film boiling and remain in the nucleate boiling regime with its higher heat transfer coefficient. We refer to this phenomenon as extended nucleate boiling (ENB) in this paper.

Earlier measurements specifically targeting heat transfer in HTS transformer applications include measurements of cooldown under load in single layer solenoid windings ${ }^{12}$ and of heat transfer from Roebel cable solenoid windings ${ }^{13}$ at low heat flux exploring the transition from natural convection to nucleate boiling in saturated vapor pressure (SVP) and subcooled LN2.

Transformer windings operate with AC current and voltage, and often with high electric fields in parts of the windings. The latter has been shown to enhance boiling heat transfer in $\mathrm{LN} 2^{14}$. In practice, the bulk of each transformer winding experiences quite low electric fields, around $50 \mathrm{~V} / \mathrm{mm}$, set by the turn to turn voltage; only the extremities of the windings are subjected to fields of $\mathrm{kV}$ per $\mathrm{mm}$.

The distinctive characteristics of HTS transformer windings from the perspective of heat transfer are:

1. Transient heating at high fault current levels sustained for up to $2 \mathrm{~s}$, raising the conductor temperature possibly as high as $450 \mathrm{~K}^{15,16,17}$

2. Recovery (cool-down) after the fault to the superconducting state, ideally while carrying rated current

3. Operation in subcooled LN2 - to lower the operating temperature for improved critical current, and to avoid boiling and the consequent risk of electrical breakdown in normal operation

4. Electrically insulated wire - in conventional transformer manufacture the insulation is typically wrapped kraft paper

5. Conductors mounted under tension in contact with insulating formers so they are able to resist the mechanical stresses of the fault current.

Accordingly, in this work we report measurements of heat transfer in LN2 from ReBCO HTS wire heated by high current pulses to temperatures as high as $300 \mathrm{~K}$. Conductor temperature and heat transfer were measured during transient heating as well as during cooling. Measurements were done in LN2 in SVP conditions at ambient pressure, with temperature of $77.4 \mathrm{~K}$, as well as subcooled, usually at $65 \mathrm{~K}$ at ambient pressure. Tapes with a range of surface treatments were investigated: bare, and with Kapton polyimide self-adhesive tape, Nomex aramid paper wrap, and with UV-cured polyurethane coatings. Finally, the heat transfer from free-standing tapes was compared with the same tapes mounted under tension in a trench milled in a composite former. Our aim was to provide the heat transfer and recovery information required to design the windings of current-limiting fault tolerant HTS transformers ${ }^{18}$. 


\section{Experimental setup}

\subsection{High current pulse and heat transfer measurement technique}

In this paper, the input power and resistance are calculated from measurements of the current and voltage across a sample $^{19}$. The temperature is calculated using a calibration of the sample resistance as a function of temperature. The samples in the present study were tapes with typical width of 4 to $5 \mathrm{~mm}$, because this is a standard form of HTS tape in large scale applications, specifically in HTS transformers. Tape samples were either brass-laminated HTS tapes (AMSC type 8700) or metallic ones such as copper and brass. Copper and brass were used as samples in this study because most commercial superconducting tapes have copper or brass stabilizer, and, current passes through the stabilizer during a short circuit fault rather than the superconductor itself. Note that the temperature determined from the resistance measurement is an average of the sample temperature. Temperature gradients through the depth of the samples will be small; for a very large heat flux of $2 \times 10^{5} \mathrm{~W} / \mathrm{m}^{2}$ normal to the tape surface, the temperature difference between the centre and surface of a $0.3 \mathrm{~mm}$ thick brass tape (thermal conductivity at $100 \mathrm{~K} \sim 50 \mathrm{~W} / \mathrm{m} \mathrm{K}$ ) will be only $0.3 \mathrm{~K}$. However, large transient temperature variations along the length of a sample are possible during the transitions between heat transfer regimes, which have been observed in HTS tape samples using high-speed photography ${ }^{20}$. Without the benefit of such observations, we maintain that the reproducibility of the results and the attainment of a stable heat flux suggest that the sample has uniform temperature and heat transfer regime along its length.

Much of the experimental work on heat transfer in literature is concerned with equilibrium conditions, with $\frac{d T}{d t}=0$, so that the input power is equal to the heat transferred. For the transient heat transfer of interest during short circuits in HTS transformers, it is necessary to take the heat capacity of the sample into account. The energy balance is expressed by:

$$
P_{\text {in }}=V C_{p v} \frac{d T}{d t}+P_{\text {out }}
$$

$P_{\text {in }}$ is the electrical power supplied to the sample, with volume $V$. The heat transfer from the sample to the liquid, $P_{\text {out }}$, is obtained by differentiating the $T(t)$ curve and using volumetric specific heat data $C_{p v}(T)$ from the literature ${ }^{21,22}$ to correct for the heat capacity of the sample. The resistivity of $\operatorname{copper}^{23}$ and brass ${ }^{24}$ is quite accurately linear in temperature in the range between $65 \mathrm{~K}$ and $300 \mathrm{~K}$, so that we calculate the temperature from the measured sample resistance by linear interpolation between measurements made at low current density at ambient temperature and at the base temperature of the cryogen. The resistance of a sample of the superconducting tape as a function of temperature was measured from room temperature to the superconducting transition to provide a temperature calibration curve for the heat transfer measurements on these samples.

The measurement setup uses a DC power supply to apply either constant current or constant voltage pulses to heat the sample. Two different power supplies were used depending on the required current level, one with $580 \mathrm{~A}, 8 \mathrm{~V}$ output and the other $1000 \mathrm{~A}, 3 \mathrm{~V}$. The current was measured using an HP3458A DVM to measure the voltage across a $0.1 \mathrm{~m} \Omega$ shunt resistance. A second HP3458A DVM measured the sample volts. The measurements of the two DVMs were synchronised, with measurements taken every $25 \mathrm{~ms}$, and each point integrated over one power line cycle, $20 \mathrm{~ms}$.

The current pulse applied to the samples consisted generally of three steps, with current levels $\mathrm{I}_{0}$, Ishort, and $\mathrm{I}_{\text {recovery. }}$ The initial current $\mathrm{I}_{0}$ was set at a level, typically $10 \mathrm{~A}$ or less, sufficient for accurate resistance measurement but with low power dissipation so that the sample temperature would deviate very little from the cryogen liquid temperature. The high current pulse Ishort then heats the sample. The recovery current was set to a range of levels: a low level, the same as Io, to record free cooling, or higher levels with appreciable dissipation to reproduce the cooling of HTS transformer windings after a short circuit. The corresponding duration of each of the current steps are $t_{0}$, $t_{\text {short}}$, and trecovery. The duration of the 
heating pulse, tshort, was typically 2 or 4 seconds when investigating heat transfer in equilibrium conditions; but was much shorter, around $0.2 \mathrm{~s}$, when the intention was to reproduce the rapid heating of HTS transformer windings during an external short circuit. Some experiments were performed with longer heating pulses of 6 or 8 seconds to confirm the equilibrium condition had been attained.

\subsection{Cryostat}

Figure 1 shows a cryostat insert for a 10-litre stainless steel thermos flask which was designed and constructed for measurements in subcooled conditions from atmospheric pressure down to $0.1 \mathrm{bar}$. The usual target conditions were those for an HTS transformer, $65 \mathrm{~K}$ at atmospheric pressure. The cryostat was divided into two levels by a thermal barrier of polystyrene foam; the upper level contained surface LN2 at $77 \mathrm{~K}$, and below it the subcooled experimental compartment. The barrier is loose-fitting so that pressure in the two levels is equalised. The subcooled compartment is cooled by evaporative cooling using a rotary pump which draws LN2 from the upper compartment through a throttling valve into a heat exchanger made from copper tube formed into a horseshoe-shaped loop. The pumping pressure is controlled by a manometer. Three PT-100 temperature sensors in the subcooled volume are used to monitor the temperature of the throttling valve and to confirm temperature uniformity at the sample location. In addition, several PT-100 sensors were used in top compartment to monitor the LN2 level so the cryostat could be periodically refilled from an external dewar.

Figure 1. Cryostat Layout showing subcooled LN2 space and copper heat exchange coil below the bottom barrier of

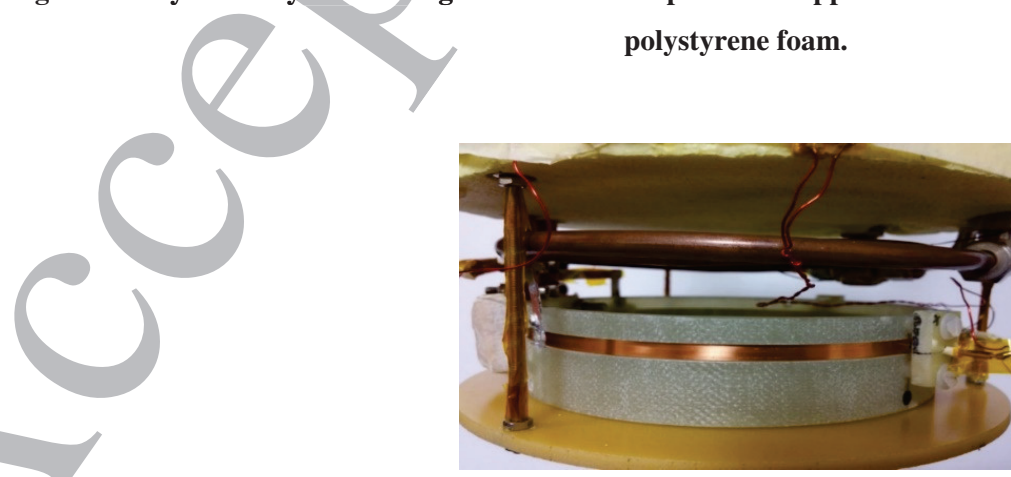

Figure 2. The sample on the former configuration in the subcooled LN2 space of the cryostat. 


\section{Experimental results and discussions}

\subsection{Heating at $77 \mathrm{~K} \mathrm{SVP}$ and subcooled LN2}

The first set of heat transfer experiments involved heating free-standing samples immersed in LN2 at $77 \mathrm{~K} \mathrm{SVP.} \mathrm{These}$ are essentially transient heating experiments, but within the 2 sec duration of the heating pulse, at lower power levels equilibrium conditions are approached: temperature tends to constant value, implying the input power is balanced by heat transfer from the tape to the LN2.

Figure 3 shows the conductor temperature versus time for constant current pulses of duration $2 \mathrm{sec}$ applied to a $0.3 \mathrm{~mm}$ thick bare copper tape immersed in LN2 at $77 \mathrm{~K}$.

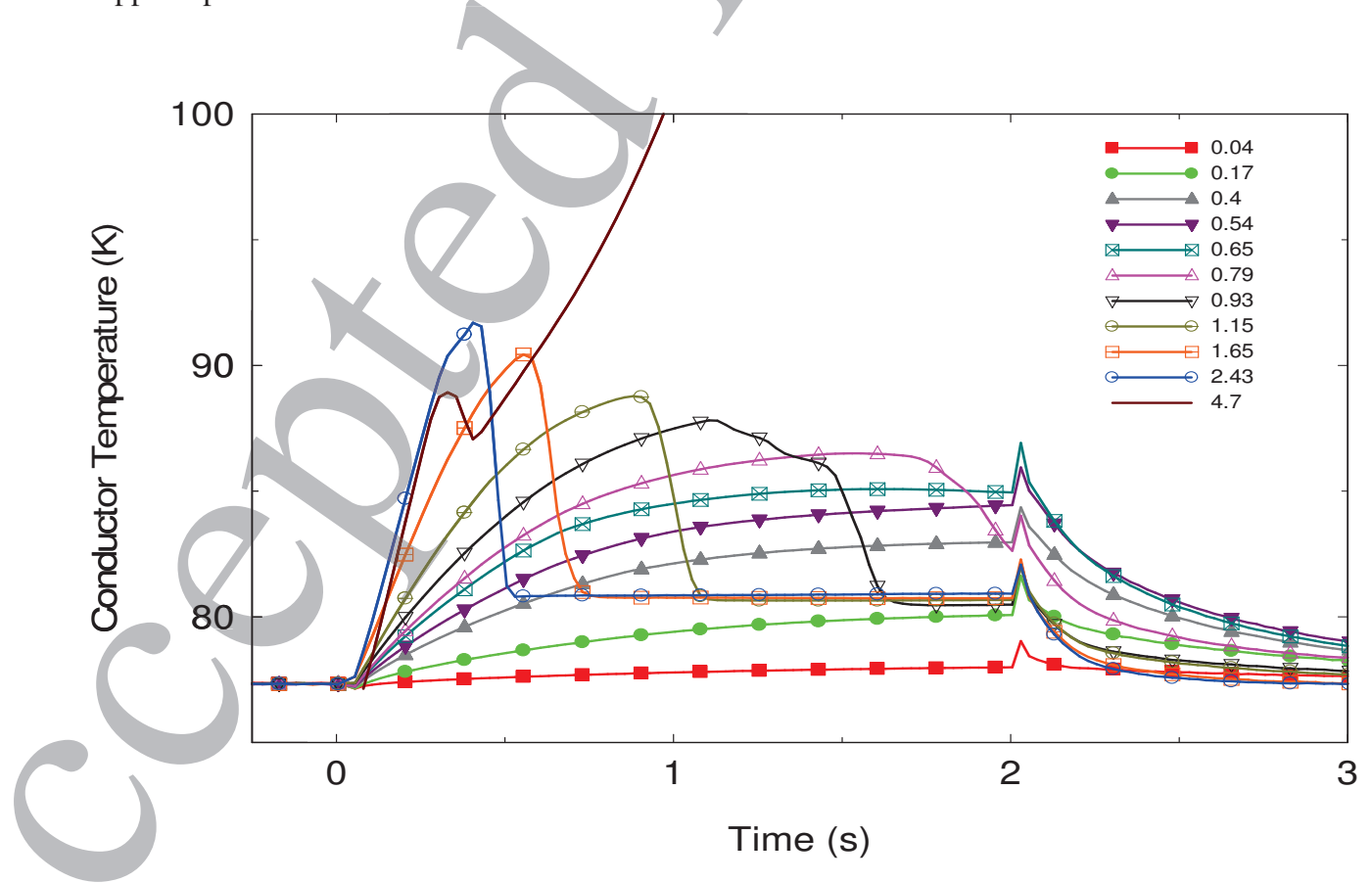

Figure 3. Conductor temperature versus time for constant current pulses of duration 2 sec for 0.3 mm thick copper tape

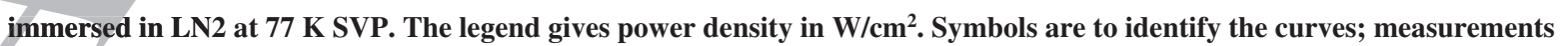
were made at $25 \mathrm{~ms}$ intervals. 
Curves are labelled with the surface power density, with the value taken to be the power density limit approached as the temperature approached its equilibrium value. Since the majority of our experiments were made on free-standing samples the surface area of both sides of the sample is used to calculate power density and heat flux unless otherwise stated. The small peaks at $2 \mathrm{~s}$ are artefacts caused by the rapid change in voltage and current at the end of the heating pulse.

Three different heat transfer regimes: natural convection, nucleate boiling, and film boiling, can be distinguished in Figure 3, as reported by other researchers who observed similar successions of transient temperature response curves ${ }^{5,25}$,as follow:

1. Convection: The conductor temperature increases monotonically to a plateau. The difference between the average temperature of the conductor and the bulk liquid nitrogen, $\Delta T$, is less than $9 \mathrm{~K}$, and current density less than 130 $\mathrm{A} / \mathrm{mm}^{2}$. The power density is up to $0.7 \mathrm{~W} / \mathrm{cm}^{2}$. At $0.93 \mathrm{~W} / \mathrm{cm}^{2}$, the temperature drop occurs in distinct steps, possibly reflecting the passage of a nucleation front as observed in high-speed camera observations ${ }^{20}$. The sample then settles at a constant temperature. This is the second heat transfer regime, nucleate boiling.

2. Nucleate Boiling: In these transient heating experiments, this state is reached after passing through a temperature peak occurring as soon as $0.3 \mathrm{~s}$ after onset of heating, with the average sample temperature reaching as high as 92 $\mathrm{K}$. The sample then experiences rapid cooling, which implies the sudden evaporation of the layer of liquid nitrogen closest to the surface. The maximum measured heat flux in the nucleate boiling regime is about $2.4 \mathrm{~W} / \mathrm{cm}^{2}$.

3. Film Boiling: In equilibrium heat transfer conditions the transition from nucleate boiling to film boiling occurs when the heat flux exceeds the critical heating flux (CHF). The heat transfer coefficient $q / \Delta T$ in film boiling is comparatively low because a sheath of vapour insulates the hot surface of the conductor from contact with the liquid nitrogen. The onset of film boiling is seen in Figure 3 at a current density of $261 \mathrm{~A} / \mathrm{mm}^{2}$, corresponding to a threshold average power density of around $4.7 \mathrm{~W} / \mathrm{cm}^{2}$. With the transition to film boiling power, thermal runaway occurs and the average conductor temperature rises to around $200 \mathrm{~K}$ by the end of the $2 \mathrm{~s}$ heating pulse.

A distinction should be made between the transition from nucleate boiling to film boiling observed in equilibrium conditions and in these transient rapid heating experiments. In equilibrium nucleate boiling conditions, a slight increase in thermal flux above the critical heating flux of around $20 \mathrm{~W} / \mathrm{cm}^{2}$ produces a boiling crisis ${ }^{26}$ with the surface drying out as LN2 can no longer reach the nucleation sites due to the volume of escaping vapour. In contrast, the transition we observe involves the surface cooling from a transient temperature maximum with $\Delta T>10 \mathrm{~K}$ to re-establish stable nucleate boiling, with $\Delta T \sim 2 \mathrm{~K}$. It is probable that the rapid onset of boiling is nucleated at the same surface nucleation sites activated at critical heating flux, rather than by homogeneous nucleation in the superheated layer of LN2 at the surface, since there is no obvious change in the $T(t)$ curves with increasing power density. At high enough power density, the heat removed from the surface by the onset of boiling is insufficient to lower its temperature into the range for stable nucleate boiling, the nucleation sites are starved of liquid, a sheath of gas surrounds the tape, and thermal runaway ensues. A further set of heat transfer experiments was conducted in subcooled LN2 at atmospheric pressure, the preferred operating conditions for HTS transformers. Transient heating experiments were performed on copper samples with longer pulses up to $4 \mathrm{~s}$ heat pulse duration. Heat transfer experiments were done at two different subcooled LN2 temperatures; $70 \mathrm{~K}$ and $65 \mathrm{~K}$. Figure 4 shows the conductor temperature versus time for constant current pulses of duration $4 \mathrm{sec}$ applied to a $0.3 \mathrm{~mm}$ thick bare copper tape immersed in subcooled LN2. We see a succession of temperature traces, similar to those at 77 K SVP in Figure 3, revealing the transition from natural convection to nucleate boiling followed by the onset of thermal runaway. At $70 \mathrm{~K}$, convective heat transfer is stable up to a conductor temperature of $85 \mathrm{~K}, \Delta \mathrm{T}=15 \mathrm{~K}$, at power density up to about $1.0 \mathrm{~W} / \mathrm{cm}^{2}$. Nucleate boiling is initiated at a power density range of $1.5 \mathrm{~W} / \mathrm{cm}^{2}$ with thermal runaway 
occurring at $6.5 \mathrm{~W} / \mathrm{cm}^{2}$. At $65 \mathrm{~K}$, convective heat transfer is stable to the same maximum conductor temperature of $85 \mathrm{~K}$, $\Delta \mathrm{T}=20 \mathrm{~K}$, to a significantly higher power density, up to about $2.1 \mathrm{~W} / \mathrm{cm}^{2}$. Nucleate boiling occurs in the power density range of $5 \mathrm{~W} / \mathrm{cm}^{2}$ to $12.6 \mathrm{~W} / \mathrm{cm}^{2}$ with thermal runaway beyond $13 \mathrm{~W} / \mathrm{cm}^{2}$.

From Figure 4, it can be concluded that the lower LN2 temperature in subcooled conditions increases the maximum heat transfer before thermal runaway, increases the maximum permissible current density before runaway, and extends the allowable temperature difference between conductor and LN2 in each heat transfer regime, which are all quite important for fault tolerant superconducting transformer applications ${ }^{18}$.

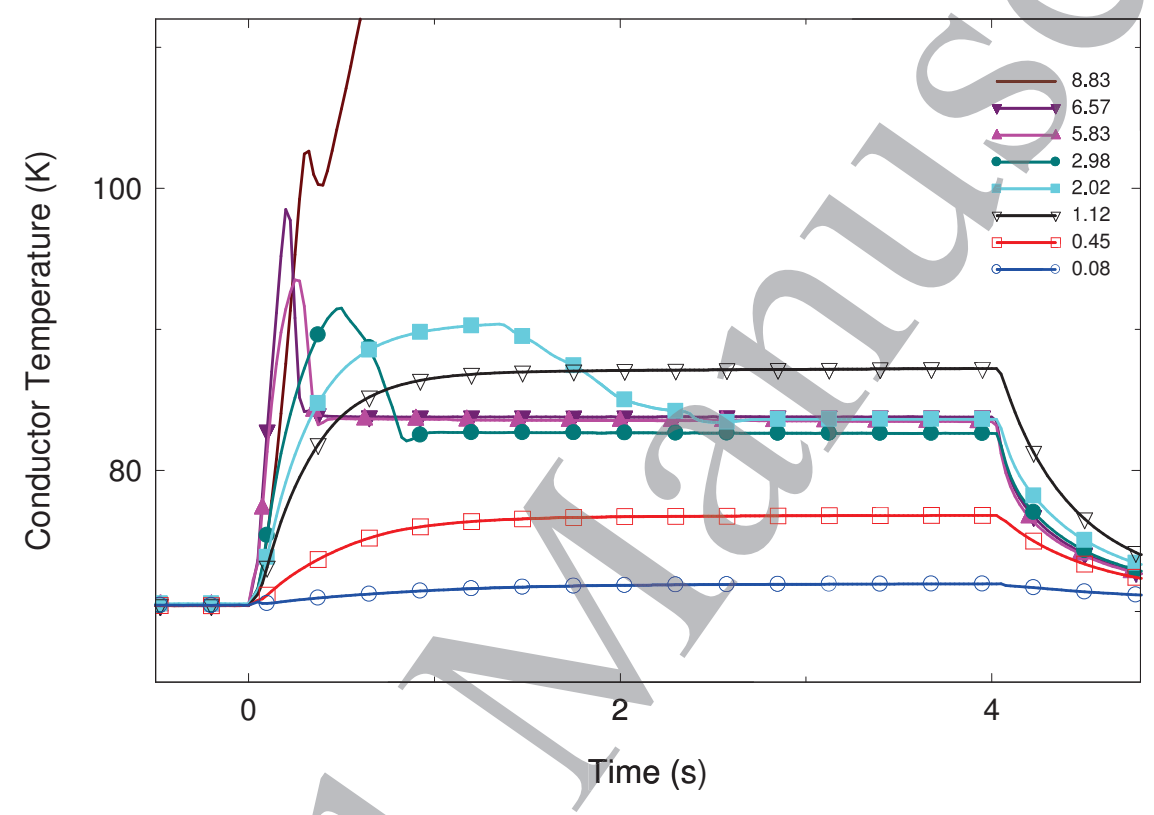

a. 70K subcooled LN2

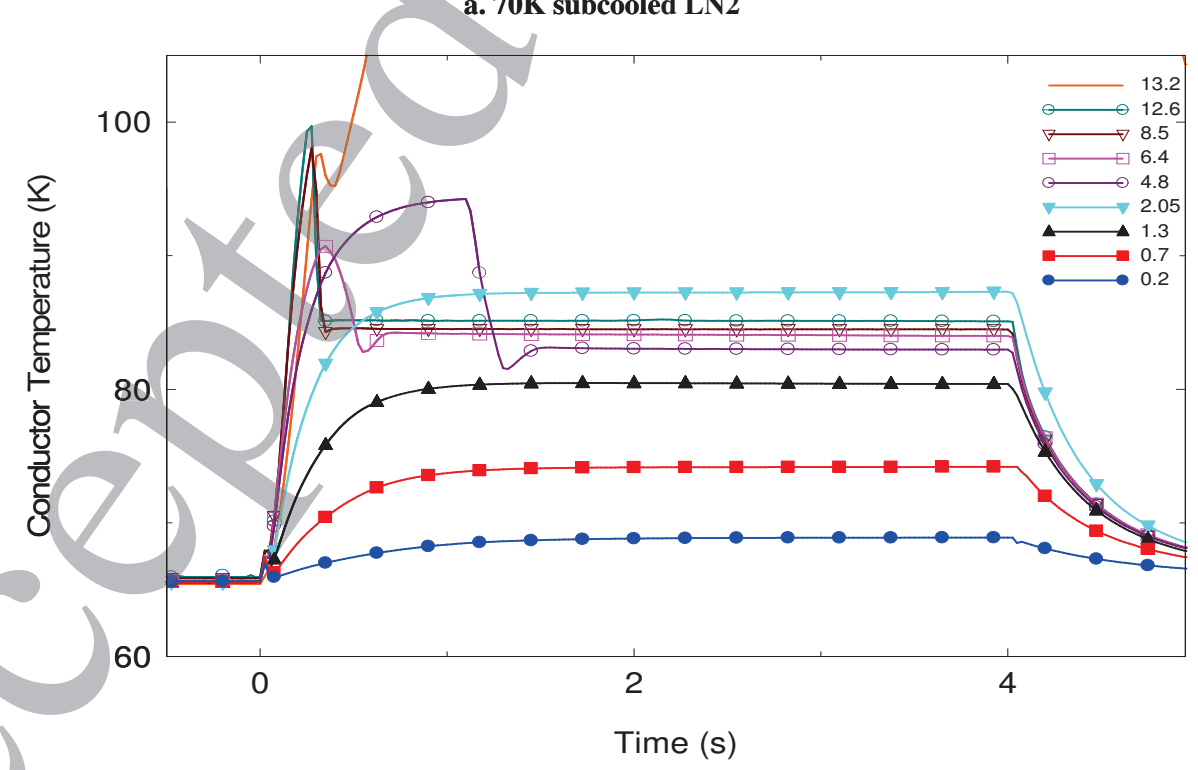

b. 65K subcooled LN2

Figure 4. Conductor temperature versus time for constant current pulses of duration $4 \mathrm{sec}$ for $\mathbf{0 . 3} \mathrm{mm}$ thick copper tape immersed in subcooled LN2 at atmospheric pressure. The legend gives power density in W/.m². Symbols are to identify the curves; measurements were made at $25 \mathrm{~ms}$ intervals. 


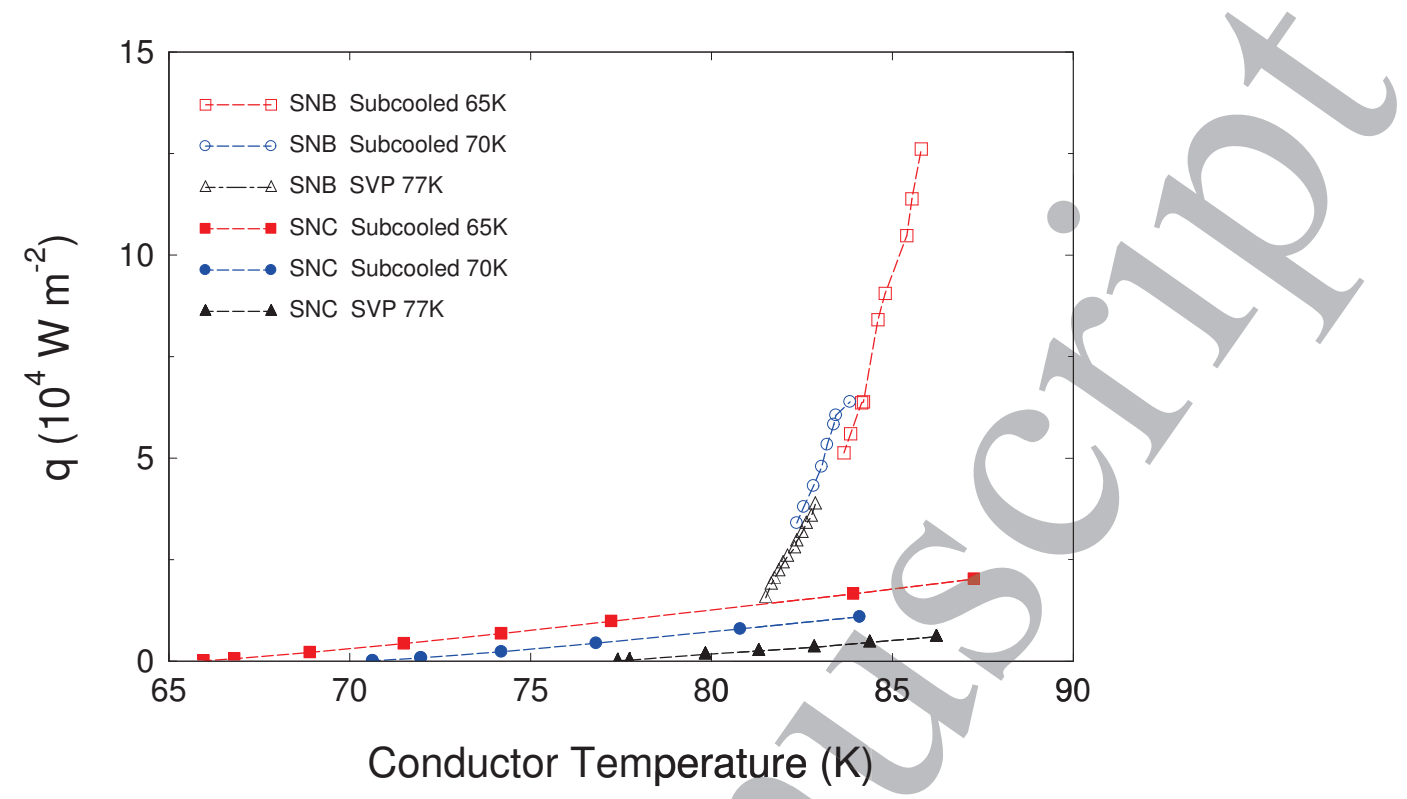

Figure 5. SNC and SNB curves versus conductor temperature for $0.3 \mathrm{~mm}$ thick bare copper tape immersed in LN2 at SVP and subcooled to 70 and $65 \mathrm{~K}$, all at atmospheric pressure

From the equilibrium temperatures and power densities in Figures 3 and 4, we can plot the heat transfer curves for stable natural convection (SNC) and stable nucleate boiling (SNB) shown in Figure 5. It can be seen that subcooling from 77 to $65 \mathrm{~K}$ increases the maximum convective heat transfer by more than a factor of $3 \mathrm{x}$, from around 0.65 to $2.1 \mathrm{~W} / \mathrm{cm}^{2}$. The SNC curves are close to linear, but are well fit by a power law with exponent slightly greater than unity, as follows:

$$
a\left(T-T_{0}\right)^{1+\delta}
$$

The fit data for the SNC curves are tabulated in Table 1.

Table 1. The fit parameters for the SNC curves derived from Figure 5

\begin{tabular}{|c|c|c|c|c|}
\hline Fit Parameters for & $T_{0}(\mathrm{~K})$ & $\mathrm{a}\left(\mathrm{W} / \mathrm{cm}^{2} \cdot \mathrm{K}\right)$ & $\delta$ & $\mathrm{q}_{\max }\left(\mathrm{W} / \mathrm{cm}^{2}\right)$ \\
\hline SVP 77K & 77.3 & 0.057 & 0.074 & 0.65 \\
\hline Subcooled 70K & 70.5 & 0.051 & 0.17 & 1.2 \\
\hline Subcooled 65K & 65.8 & 0.059 & 0.15 & 2.1 \\
\hline
\end{tabular}

The obvious feature of the SNC curyes is that they are displaced along the temperature axis i.e. they scale with $\Delta T=T-$ $T_{0}$, with the base temperature $T_{0}$ changing with the different LN2 temperatures. They terminate at a common maximum temperature around $87 \mathrm{~K}$ corresponding to the maximal superheating for the sample surface in these transient heating conditions. In contrast the heat transfer curves for stable nucleate boiling at different LN2 temperatures shown in Figure 5 seem to be segments of a single curve, with heat flux depending only on the conductor temperature. This perhaps reflects the fact that the latent heat of vaporisation of the liquid, at $199 \mathrm{~kJ}^{\mathrm{kg}} \mathrm{kg}^{-127}$, dominates the boiling heat transfer compared to the specific heat required to raise the liquid temperature to that of the conductor, $2 \mathrm{~kJ} \cdot \mathrm{kg}^{-1} \cdot \mathrm{K}^{-1}$. The effect of lowering the temperature of the LN2 below $77 \mathrm{~K}$ is mostly to alter the range of heat flux in which stable nucleate boiling can be maintained. In particular, the maximum heat flux attainable before thermal runaway intervenes is increased. This can be 


\subsection{Cooling and recovery phase}

Heat transfer measurements during transient cooling from around $300 \mathrm{~K}$ are considered in this section. This type of heat transfer study is very important for predicting the recovery of the windings of an HTS transformer after a short circuit fault. We compare heat transfer in 3 conditions: subcooled $67 \mathrm{~K}$ and SVP $77 \mathrm{~K}$, both at atmospheric pressure, and SVP $64 \mathrm{~K}$, at a nominal pressure of 0.145 bar.

To measure the heat flux in cooling from around $300 \mathrm{~K}$, we aim to mimic conditions during a short circuit fault of superconducting power transformers, heating the conductor in near-adiabatic conditions to minimise heat transfer during the heating pulse. Therefore, we heat the sample with a high current pulse of duration less than $0.35 \mathrm{~s}$. This is difficult to achieve repeatedly with copper tapes in constant current mode measurements. The rapid increase in the resistivity of pure copper with temperature $(\rho(300 \mathrm{~K}) / \rho(77 \mathrm{~K})>7)$ means that $\frac{d T}{d t} \propto \rho J^{2}$ can be extremely high, and any slight inhomogeneity in heat transfer produces positive feedback so the tape easily becomes subject to non-uniform heating, evidenced by locally discoloured hotspots observed after some of measurements and by frequent burn-out of samples. Consequently, we used constant voltage excitation for the heating pulse as well as using brass samples, for which $\rho(300 \mathrm{~K}) / \rho(77 \mathrm{~K})$ $\sim 1.5$, for some of the cool-down experiments.

Figure 6 shows conductor temperature versus time for constant voltage pulses of different duration in a $0.3 \mathrm{~mm}$ thick copper tape immersed in LN2 at 77K SVP including the cool-down, and recovery measured with much lower current density $\left(\sim 7 \mathrm{~A} \cdot \mathrm{mm}^{-2}\right)$ and negligible input power level. Short pulses of different duration were applied to the sample. Table 3 lists maximùm temperature, corresponding pulse energy, and cool-down time for this test.

Figure 7 shows the maximum temperature as a function of the pulse energy and the maximum temperature calculated from the specific heat assuming adiabatic heating. The results show that heating is near-adiabatic for heating at these high rates, at peak power from 25 to $75 \mathrm{~W} / \mathrm{cm}^{2}$ of surface area. Fully $93 \%$ of the power is used to heat the tape, and only $7 \%$ transferred to the LN2 during the heating pulse. 


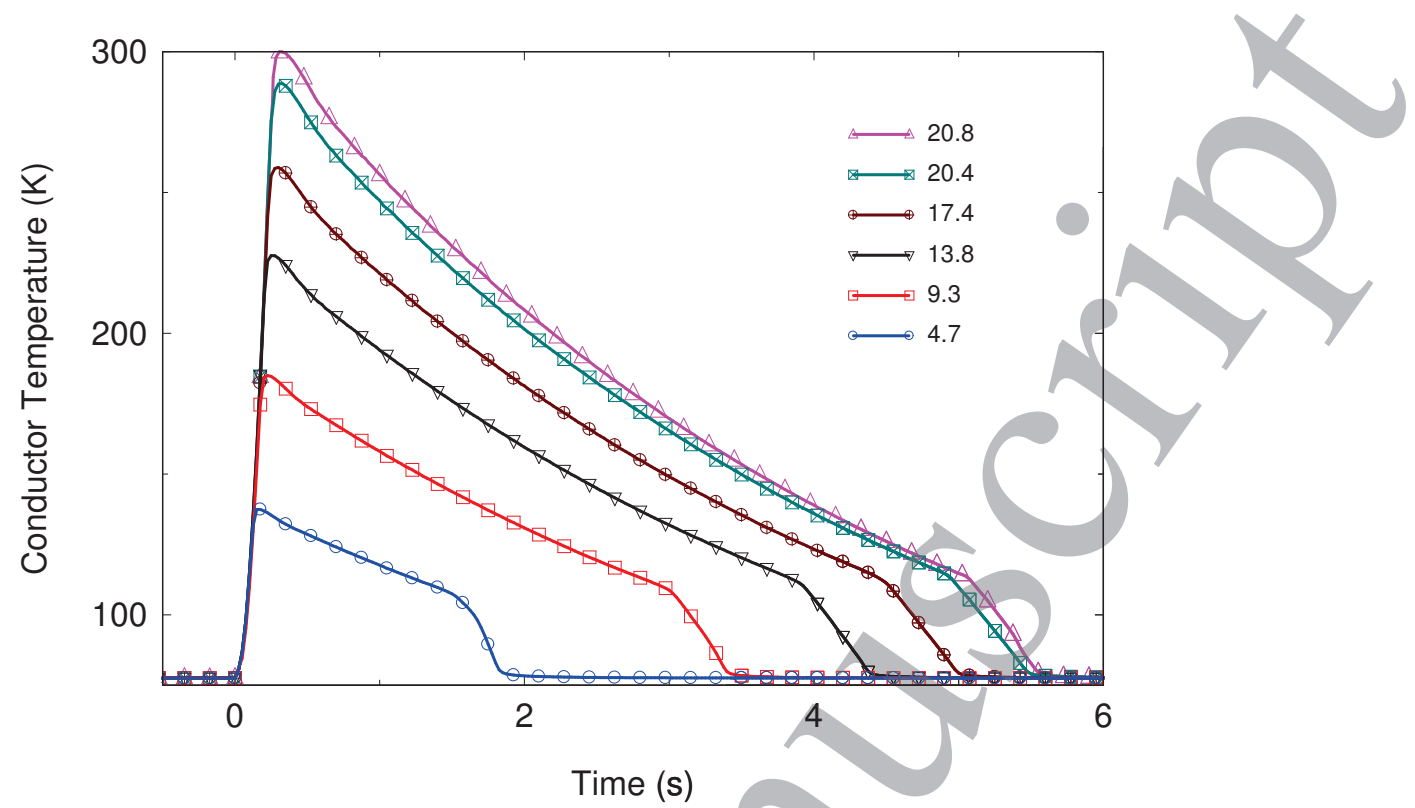

Figure 6. Conductor temperature versus time for constant voltage pulses of different duration in $0.3 \mathrm{~mm}$ thick copper tape immersed in LN2 at 77K SVP showing cool-down from different maximum temperatures. The legend gives pulse energy in

$$
\mathrm{J} / \mathrm{cm}^{2}
$$

Table 3. The maximum temperature, heating pulse energy, and cool-down time for the rapid heating experiments of Figure 6

\begin{tabular}{|c|c|c|c|c|c|c|}
\hline Maximum Temperature (K) & 137 & 185 & 228 & 260 & 288 & 300 \\
\hline Corresponding Pulse Energy $\left(\mathrm{J} / \mathrm{cm}^{2}\right)$ & 4.7 & 9.3 & 13.8 & 17.4 & 20.4 & 20.8 \\
\hline Cool-Down Time (s) & 1.9 & 3.4 & 4.6 & 5.1 & 5.6 & 5.7 \\
\hline
\end{tabular}

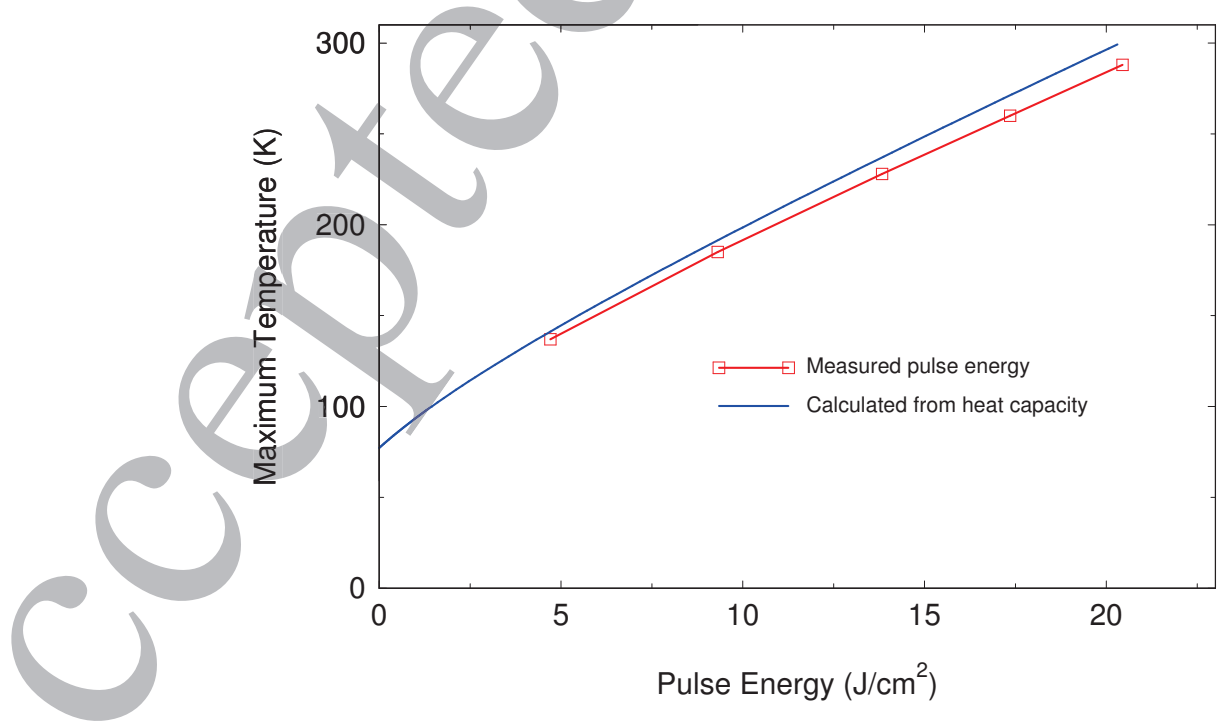

Figure 7. Maximum temperature reached after high current pulses of duration around $0.2 \mathrm{~s}$ as a function of energy delivered by the pulse. The maximum temperature predicted using heat capacity data from the literature is shown by the solid line. 


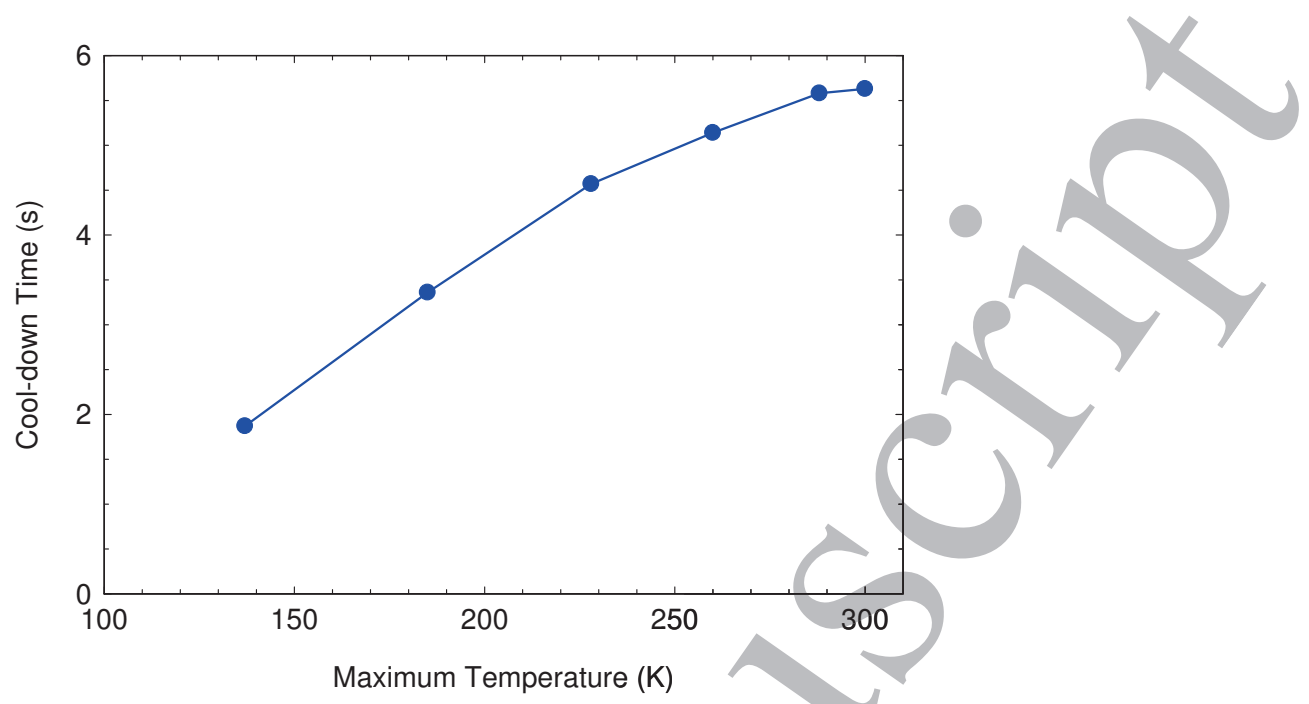

Figure 8. Cool-down time for free-standing $5 \times 0.3 \mathrm{~mm}$ copper tape in $\mathrm{LN} 2$ at $77 \mathrm{~K} \mathrm{SVP}$ as a function of initial temperature

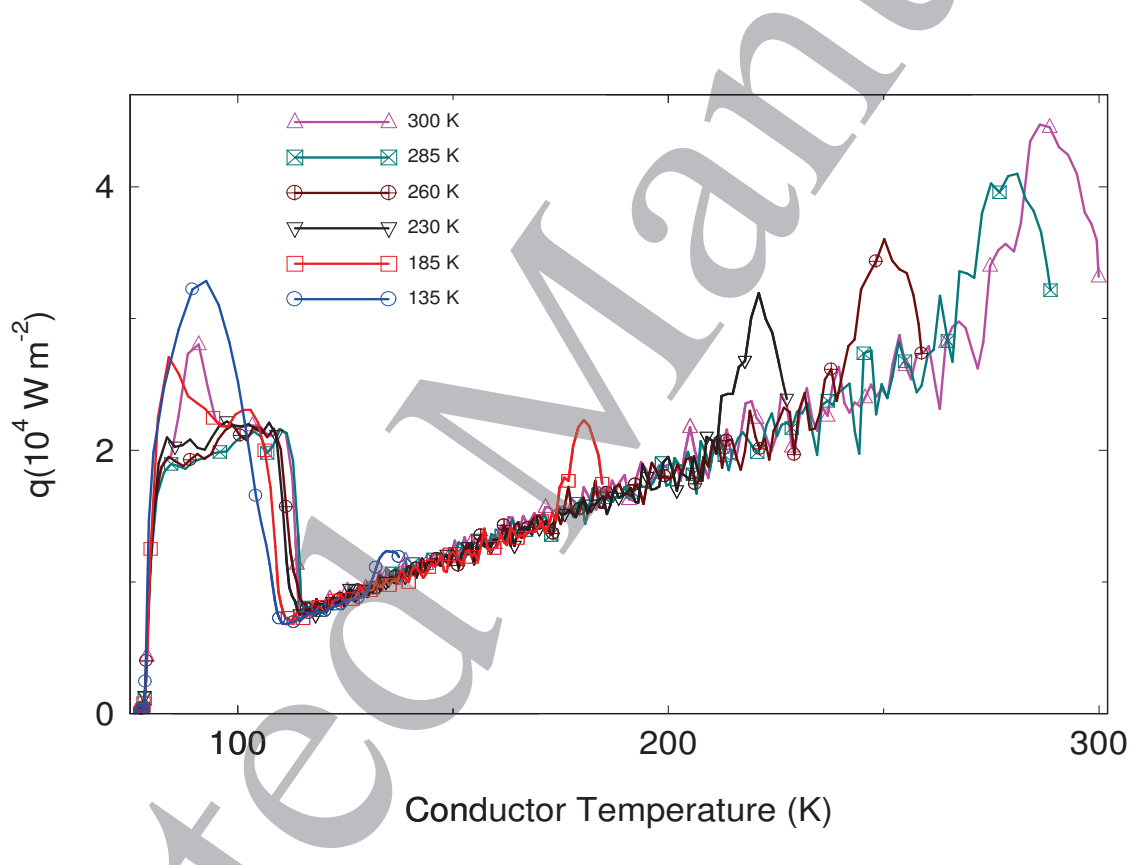

Figure 9. Heat transfer versus conductor temperature during cool-down starting from various maximum temperatures for a $0.3 \mathrm{~mm}$ thick copper tape immersed in LN2 at 77K SVP.

Figure 8 shows the cool-down time as a function of maximum temperature. The cool-down time for this $5 \mathrm{x} 0.3 \mathrm{~mm}$ copper tape appears to be approaching a limit at around $6 \mathrm{~s}$ as the maximum temperature reaches $300 \mathrm{~K}$.

Figure 9 shows the heat transfer versus conductor temperature for cooling from different maximum temperatures calculated from the cooling portions of the $\mathrm{T}(\mathrm{t})$ curves of Figure 6. In each case, heat transfer declines at first almost linearly from the maximum temperature in the film boiling regime. After reaching the Leidenfrost minimum ${ }^{28}$ at $110-$ $115 \mathrm{~K}$, the heat transfer increases as nucleate boiling is initiated. Apart from the initial artefact peak, the film boiling curves are remarkably reproducible, and independent of $\mathrm{T}_{\max }$. The nucleate boiling peaks are much more variable, reflecting perhaps the stochastic nature of nucleation, since the peak is traversed in little more than $0.2 \mathrm{~s}$ in the steep final section of the cooling curves in Figure 6 . The peak values of around $3 \mathrm{~W} / \mathrm{cm}^{2}$ are consistent with the maximum heat transfer from stable nucleate boiling in LN2 at 77 K SVP shown in Figure 5. 
HTS tape with brass stabilizer is a promising option for manufacturing HTS transformer windings ${ }^{18}$, as well as SFCLs. For this reason, the effect of subcooling on heat transfer in the cooling phase was investigated using a $0.9 \mathrm{~mm}$ thick 5.6 mm wide brass sample. In addition, the thicker brass samples, with greater heat capacity, cool more slowly, reducing the measurement uncertainty. From the results shown in Figure 10 it is clear that, at 1 bar, the heat transfer in subcooled LN2 is higher than in the SVP condition. The peak nucleate boiling heat transfer in subcooled LN2 at $67 \mathrm{~K}$ is about $2.5 \mathrm{x}$ that at $77 \mathrm{~K} \mathrm{SVP}$. In the film boiling regime also the heat transfer in subcooled LN2 is about 50\% higher than $77 \mathrm{~K} \mathrm{SVP.} \mathrm{The}$ nucleate boiling peak in the subcooled LN2 occurs at around $105 \mathrm{~K}$, and the Leidenfrost minimum, at which the transition from film boiling to nucleate boiling begins, is at $150-160 \mathrm{~K}$. Another interesting observation is that the heat transfer at $67 \mathrm{~K}$ subcooled is even higher than $64 \mathrm{~K} \mathrm{SVP}$. The Leidenfrost minimum and nucleate boiling peak for the heat transfer curves in $77 \mathrm{~K}$ and $64 \mathrm{~K} \mathrm{SVP} \mathrm{LN} 2$ and are displaced in temperature by approximately the $13 \mathrm{~K}$ difference in saturation temperature at $1 \mathrm{~atm}$ and 0.145 bar. The film boiling heat transfer at 0.145 bar (64 K SVP) is reduced compared to 1 bar (77 K SVP) presumably because a smaller rate of liquid evaporation is required to maintain a given average thickness of the insulating vapour film at the lower pressure. These results are very significant for the design of HTS transformers. Operation in subcooled LN2 is beneficial, not only to improve the critical current and AC loss of the wire and to avoid the bubble-induced reduction in breakdown voltage of the LN2 dielectric, but also to improve heat transfer for better performance during recovery after a short circuit $^{18}$ fault.

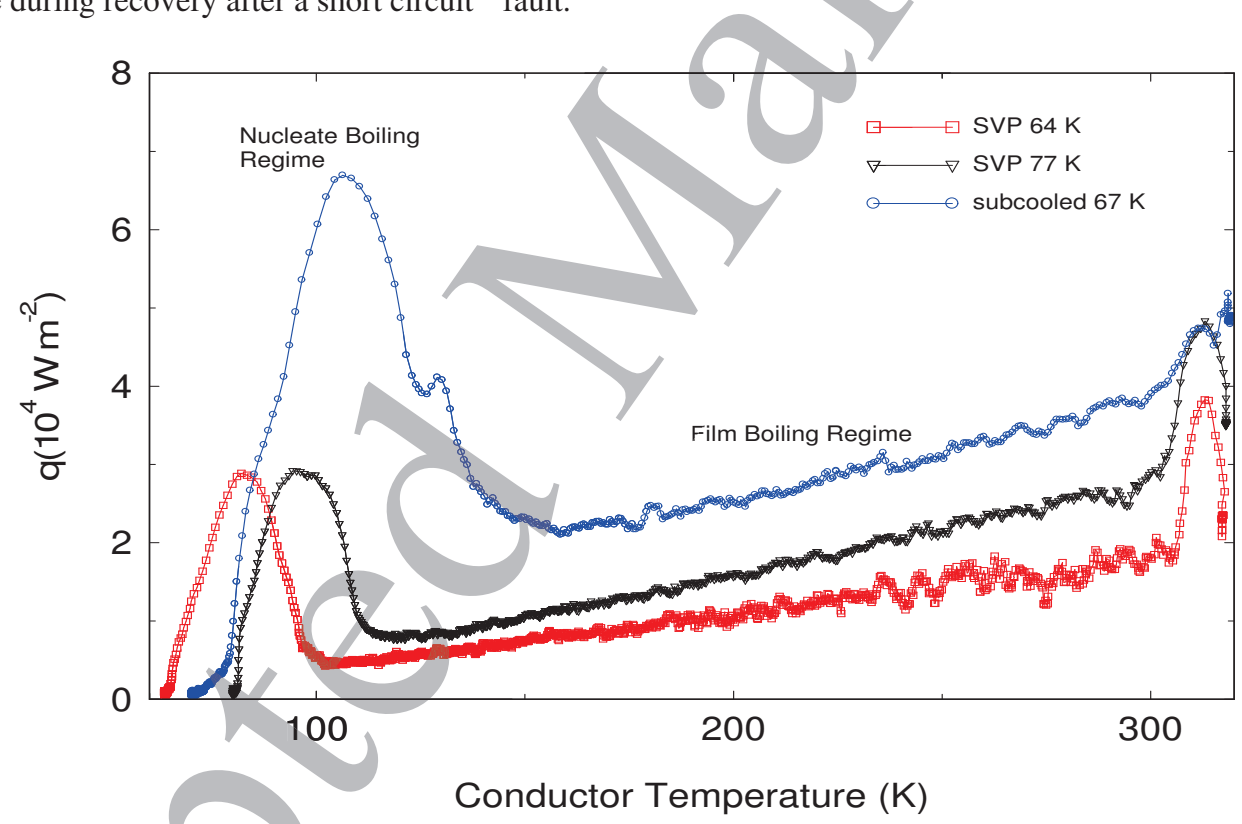

Figure 10. Heat transfer of bare brass tape in LN2 subcooled to $67 \mathrm{~K}$ at 1 bar, and at SVP at 1 bar (77 K), and 0.145 bar (64 K)

\subsection{Effect of conductor coatings on heat transfer performance during a short circuit fault}

A major aim for these heat transfer studies was to provide information to guide the design and materials selection for a $45 \mathrm{kVA}$ fault tolerant transformer demonstration ${ }^{18}$. The wire selected for the demonstrator (based on the results of this paper) was AMSC type 8700 type Amperium wire, a brass-laminated wire, $0.44 \mathrm{~mm}$ thick and $4.4 \mathrm{~mm}$ wide with tinned brass external surfaces. To ensure that the heat transfer characteristics of coatings applied to the HTS wire were representative of those obtained using a long-length coating system, type 8700 wire was adopted as sample material for these heat transfer measurements. A measurement of wire resistance as a function of temperature from the conductor's critical temperature at around $90 \mathrm{~K}$ to $300 \mathrm{~K}$ was done to provide the temperature calibration curve needed for heat transfer experiments. The critical current of the HTS tape was measured to be 109 A at $77 \mathrm{~K}, 272 \mathrm{~A}$ at $65 \mathrm{~K}$. 
Short samples ( $0.55 \mathrm{~m}$ length) of the Type 8700 wire were coated using a Mayer rod coating system to apply UV-cured polyurethane (PU) resin coatings with 4 different nominal coating thicknesses: 45, 55, 100, and $120 \mu \mathrm{m}$. The measured average thicknesses of the coatings were 44.2, 56.6, 101.2, and $120.7 \mu \mathrm{m}$ with standard deviation between 1 and $2 \mu \mathrm{m}$. Kapton polyimide adhesive tape has been used as wrapped turn-to-turn insulation in HTS transformers ${ }^{29}$. For comparison with the PU coatings of a uniform thickness of Kapton adhesive tape, the bare HTS wire was sandwiched between two strips of $10 \mathrm{~mm}$-wide tape with the edges of the adhesive tape extending beyond the edges of the wire carefully sealed together. Figure 11(a),11(b) show conductor temperature versus time and heat transfer versus conductor temperature plots respectively for AMSC 8700 type HTS tapes with different coating thicknesses immersed in subcooled LN2 at $65 \mathrm{~K}, 1$ bar pressure. The HTS tapes were heated to temperatures around $300 \mathrm{~K}$ with high current pulses of duration 0.27 to 0.38 s. Measurements during the cool-down phase were made with a current of $10 \mathrm{~A}$ flowing, corresponding to input power of around $450 \mathrm{~W} / \mathrm{m}^{2}$ at $300 \mathrm{~K}$, dropping to half this at $90 \mathrm{~K}$. This is negligible as it is only about $1 \%$ of the lowest heat transfer flux measured. Note that the apparent rapid cooling at the end of each trace apart from that for the bare tape reflects the transition to the superconducting state, which makes accurate temperature measurements impossible below about $90 \mathrm{~K}$. The increase in slope below $150 \mathrm{~K}$ for the bare conductor marks the transition to nucleate boiling for this sample.

It is apparent from Figure 11(a) that the PU coated conductors cool more rapidly than the bare and the Kapton coated conductors. The conductors with the thinner PU coating, 45 and $55 \mu \mathrm{m}$, initially cool more slowly than the conductors with thicker coatings, but the rate of cooling then increases rapidly, so that they have the shortest cool-down times, well under $1 \mathrm{~s}$. This variation in heat transfer with temperature is reflected in the heat transfer curves in Figure 11(b) which show that the heat transfer with the 40 and $55 \mu \mathrm{m}$ coatings peaks at around 170 and $200 \mathrm{~K}$ respectively, whereas with the thicker PU coatings, the heat transfer declines continuously during cool-down. The conductor with the $55 \mu \mathrm{m}$ PU thickness has the highest heat transfer peak, close to $27 \mathrm{~W} / \mathrm{cm}^{2}$, more than $8 \mathrm{x}$ higher than the bare conductor heat transfer in this temperature range. Compared with the bare HTS tape at 77K SVP, the recovery time and maximum heat transfer of the coated sample with the $55 \mu \mathrm{m}$ PU in $65 \mathrm{~K}$ subcooled LN2 are 7x shorter and 15x higher, respectively. The large solid circles indicate measurements derived from SNB states encountered during cool-down under load of the HTS wire with $55 \mu \mathrm{m}$ PU coating, to be described in section 3.4.

Because of its superior heat transfer, a PU coating with thickness $55 \mu \mathrm{m}$ was selected for the wire for the fault tolerant HTS transformer winding ${ }^{18}$.

Solid coatings are effective at extending the range of conductor temperature over which nucleate boiling occurs because they allow the conductor temperature to exceed the temperature of the interface between coating and liquid by the temperature drop across the coating thickness. Considering the peak in nucleate boiling heat transfer, this can be expressed:

$$
T_{\text {cond } p k}=T_{N B p k}+d_{c} q_{N B p k} / \kappa_{c}
$$

Where $q_{N B} p k$ is the peak nucleate boiling heat transfer, $T_{\text {cond } p k}$ is the conductor temperature and $T_{N B p k}$ is the temperature, assumed constant, of the surface of the coating at peak heat transfer, $d_{c}$ is the thickness of the coating, and $\kappa_{c}$ is its average thermal conductivity. Figure 12 shows the temperature of the peak in heat transfer plotted against $d_{c} q_{N B} p k$. The fit excludes the last point, for the $120 \mu \mathrm{m}$ coating, which is perhaps affected by transients at the onset of cooling. The points lie on a straight line. The inverse of the slope gives the average thermal conductivity of the coating, assumed constant even though the temperature of the coating at peak heat transfer can be inferred to span a range of about 
110 to $160 \mathrm{~K}$ for the thinnest coating, up to 110 to $230 \mathrm{~K}$ for the thickest. The average thermal conductivity from the slope is $0.19 \mathrm{~W} / \mathrm{m} . \mathrm{K}$ which is in good agreement with typical values for polymers in this temperature range ${ }^{30}$. The intercept predicts that the conductor temperature at peak heat transfer for a zero-thickness coating should be $108 \mathrm{~K}$, in good agreement with our measurements on non-superconducting tapes.

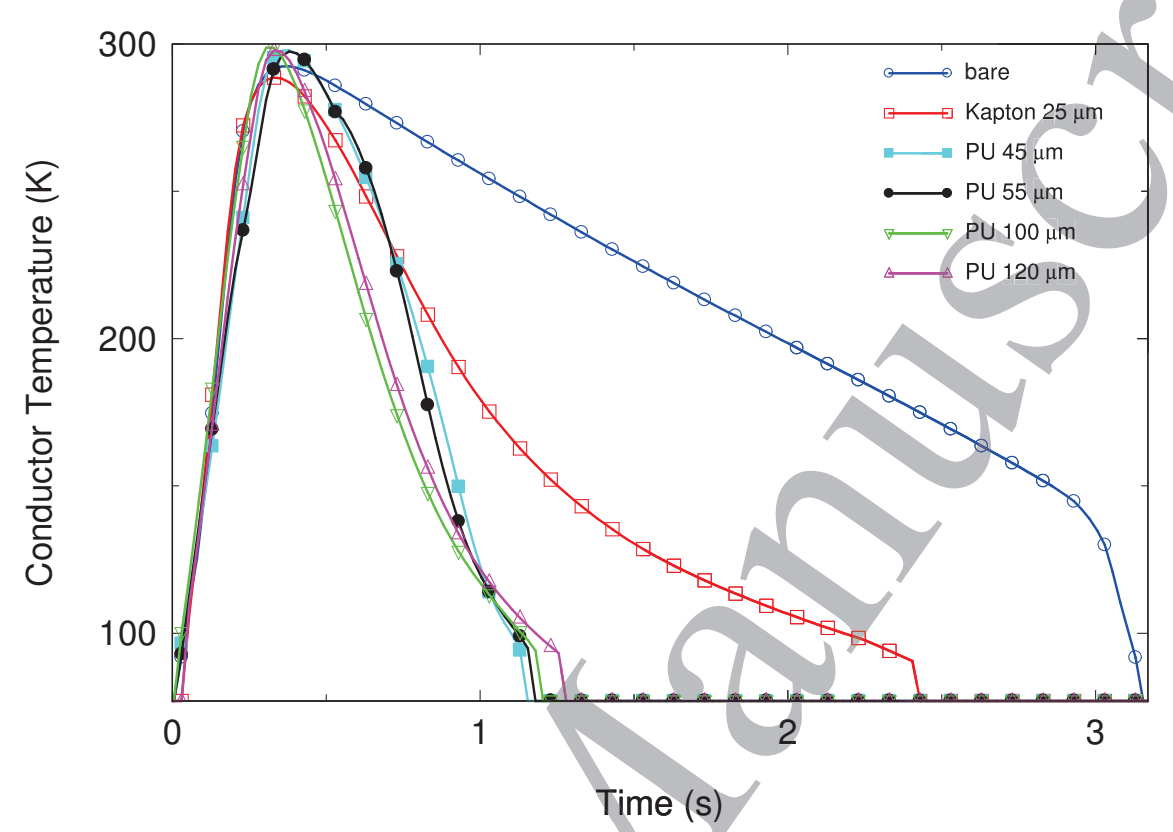

a. Conductor temperature versus time.

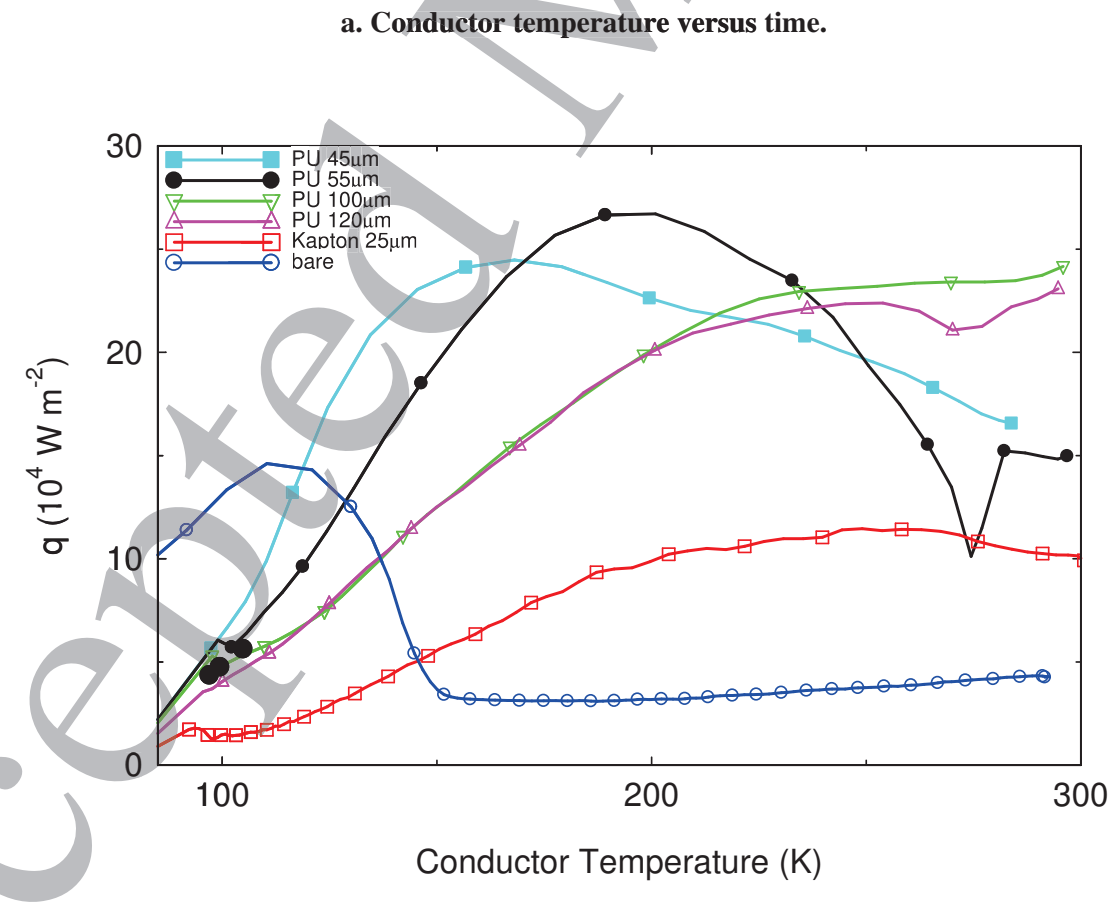

b. Heat transfer during cooling versus conductor temperature (Large solid circles are from recovery current measurements).

Figure 11. Thermal performance of AMSC 8700 type HTS samples with different coating thicknesses immersed in $65 \mathrm{~K}$

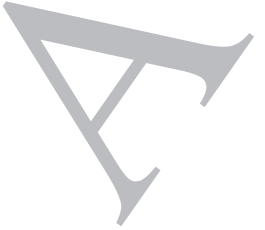
subcooled LN2. 


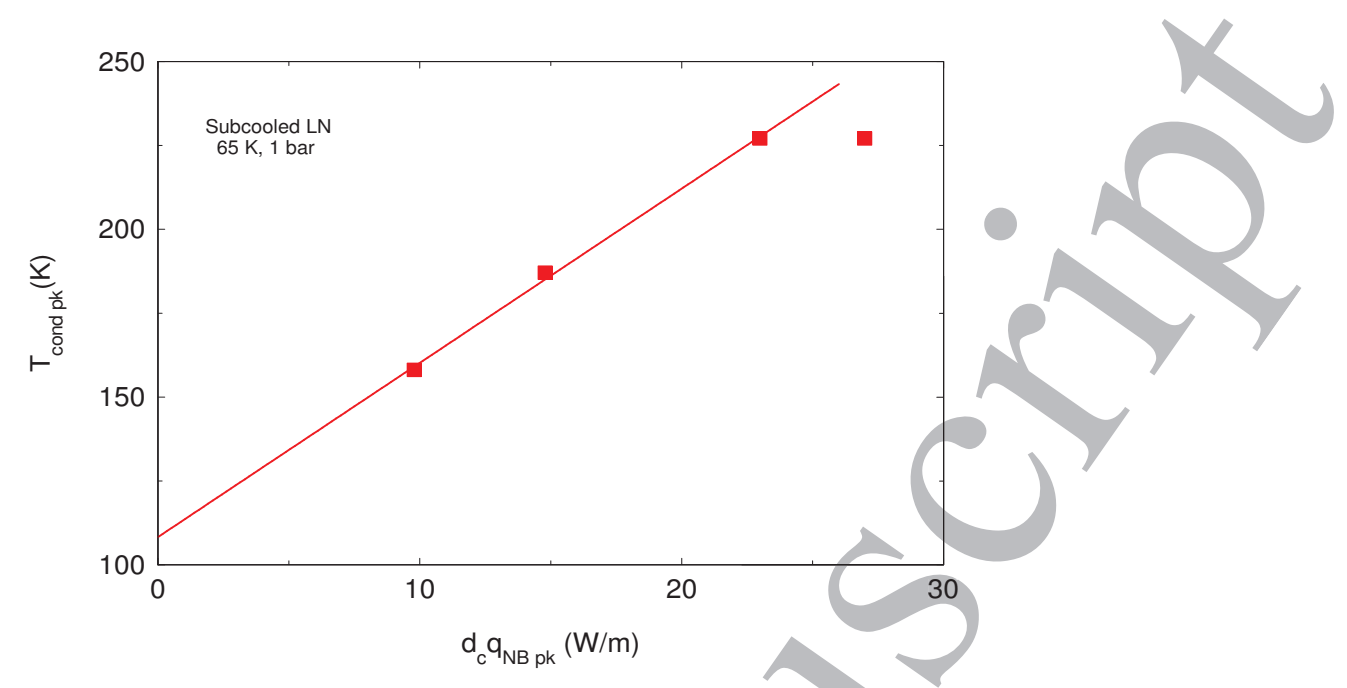

Figure 12. Dependence of conductor temperature at peak heat transfer on the product of coating thickness and heat transfer at the nucleate boiling peak. The line is a linear fit excluding the last point

While they can significantly increase boiling heat transfer, coatings will reduce the convective heat transfer by adding the thermal resistance of the coating in the heat conduction path. The convective heat transfer coefficient for bare conductors is given by the slope of the curves in Figure 5. A representative value is $h=800 \mathrm{Wm}^{-2} \mathrm{~K}^{-1}$. The effective conductive heat transfer coefficient for the coating is given by $h_{c c}=\frac{\kappa_{c}}{d_{c}}$, with a value around $3400 \mathrm{Wm}^{-2} \mathrm{~K}^{-1}$, assuming a $55 \mu \mathrm{m}$ thick coating with conductivity of $0.19 \mathrm{Wm}^{-1} \mathrm{~K}^{-1}$. The ratio of the convectiye heat flux with coating in place relative to the bare conductor at the same conductor temperature is given by $\frac{q_{c}}{q_{0}}=\frac{h_{c c}}{h_{c c}+h}$. The convective heat flux with coating in place is reduced in this case to $81 \%$ of that for the bare conductor.

\subsection{Recovery under load}

Power transformers are expected to continue to operate at rated current after the short circuit fault is isolated. HTS transformer windings need to have, along with high heat transfer, low enough resistance to allow them to cool down to regain the superconducting state while carrying substantial current in the metal stabiliser of the wire.

Figure 13 shows cool-down curves for a $0.3 \mathrm{~mm}$ thick copper tape with $55 \mu \mathrm{m}$ PU coating in subcooled LN2 at $70 \mathrm{~K}, 1$ bar. The sequence of curves is for increasing current levels flowing during the recovery period, the cool-down interval following the high current heating pulse. For the last curve in the sequence, a high current pulse of $194 \mathrm{~A}$ was applied for $1 \mathrm{~s}$, before dropping the current to $10 \mathrm{~A}$ to allow recovery. The average power dissipated in the stabiliser during this pulse, $4.75 \mathrm{~W} / \mathrm{cm}^{2}$, just balanced the heat transfer to the LN2. The measured input power with $\frac{d T}{d t}=0$ then serves as an independent check on the heat transfer calculated using $V C_{p v} \frac{d T}{d t}$ in Equation (1), which depends on $C_{p v}$ reference data and on the calibration of conductor resistance versus temperature. With the recovery current held constant at a slightly lower level, at $190 \mathrm{~A}$, the copper tape cools down to near the base temperature. The final temperature exceeds the base temperature by an amount proportional to the square of the recovery current. The corresponding heat transfer coefficient of around $600 \mathrm{Wm}^{-2} \mathrm{~K}^{-1}$ is consistent with the convective heat transfer data in Figure 5.

Figure 14 shows the results of recovery current measurements on an HTS tape with $55 \mu \mathrm{m}$ PU coating. Below the $90 \mathrm{~K}$ critical temperature of the HTS wire, its resistance does not give a reliable measure of conductor temperature. However, the power dissipated at constant current clearly shows when the wire has regained the superconducting state. At recovery currents of 125 A and above, the cool-down "stalls" at tape temperatures between 95 and $110 \mathrm{~K}$. At 110 A recovery 
current, the tape resistance corresponds to a temperature below $90 \mathrm{~K}$ and is continuing to drop slowly. At 90 A recovery current, the rapid drop in dissipation below a threshold at about $1 \mathrm{~W} / \mathrm{cm}^{2}$ marks the recovery of the superconducting state. The power density plateaux at $125 \mathrm{~A}$ and above allow us to estimate the equilibrium nucleate boiling heat transfer points shown in Figure 11; they are in very good agreement with the curve calculated from the free-cooling temperature record. Table 4 summarises the results of the cool-down heat transfer measurements in subcooled LN2 at 65 K, 1 bar, on HTS samples with different coating thicknesses.

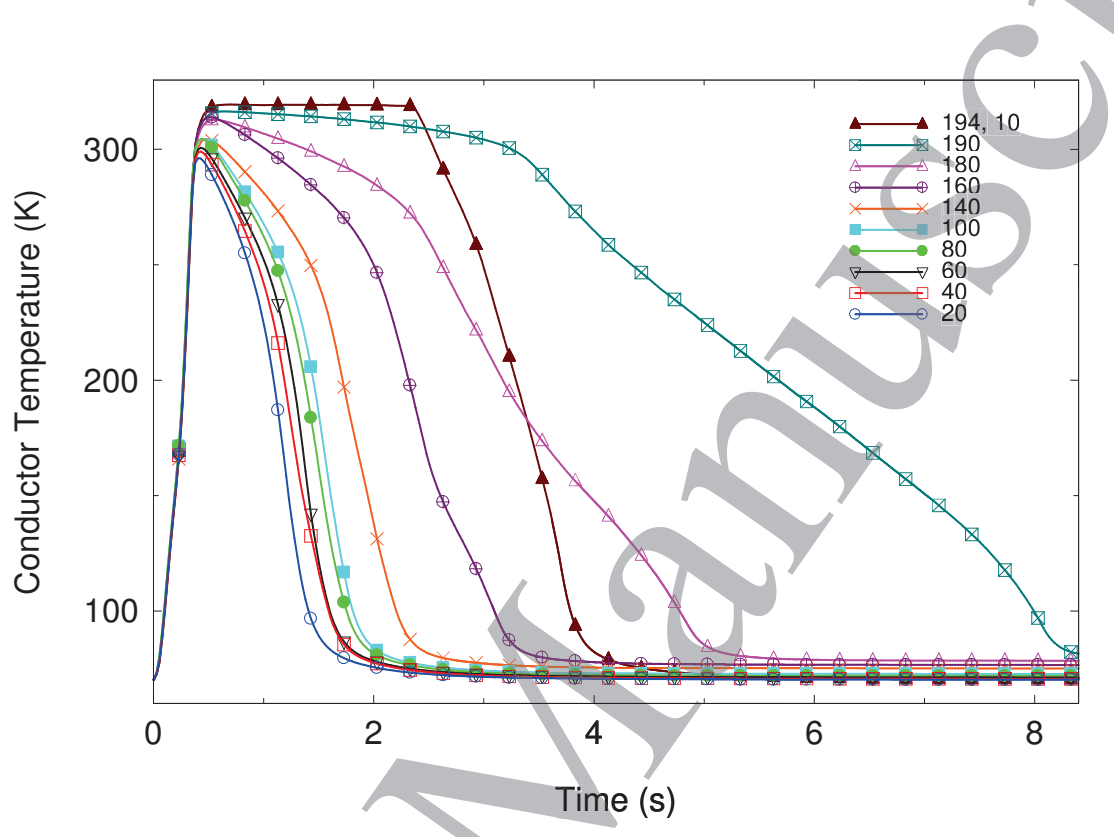

Figure 13. Cool-down curves for thick copper tape with $55 \mu \mathrm{m}$ PU coating with current flowing during the recovery period measured in subcooled LN2 at $70 \mathrm{~K}, 1$ bar. The conductor was heated to around $300 \mathrm{~K}$ with a $0.33 \mathrm{~s}$ duration high current pulse of $925 \mathrm{~A}$, followed by the application of a recovery current as described in the text. The legend gives the recovery

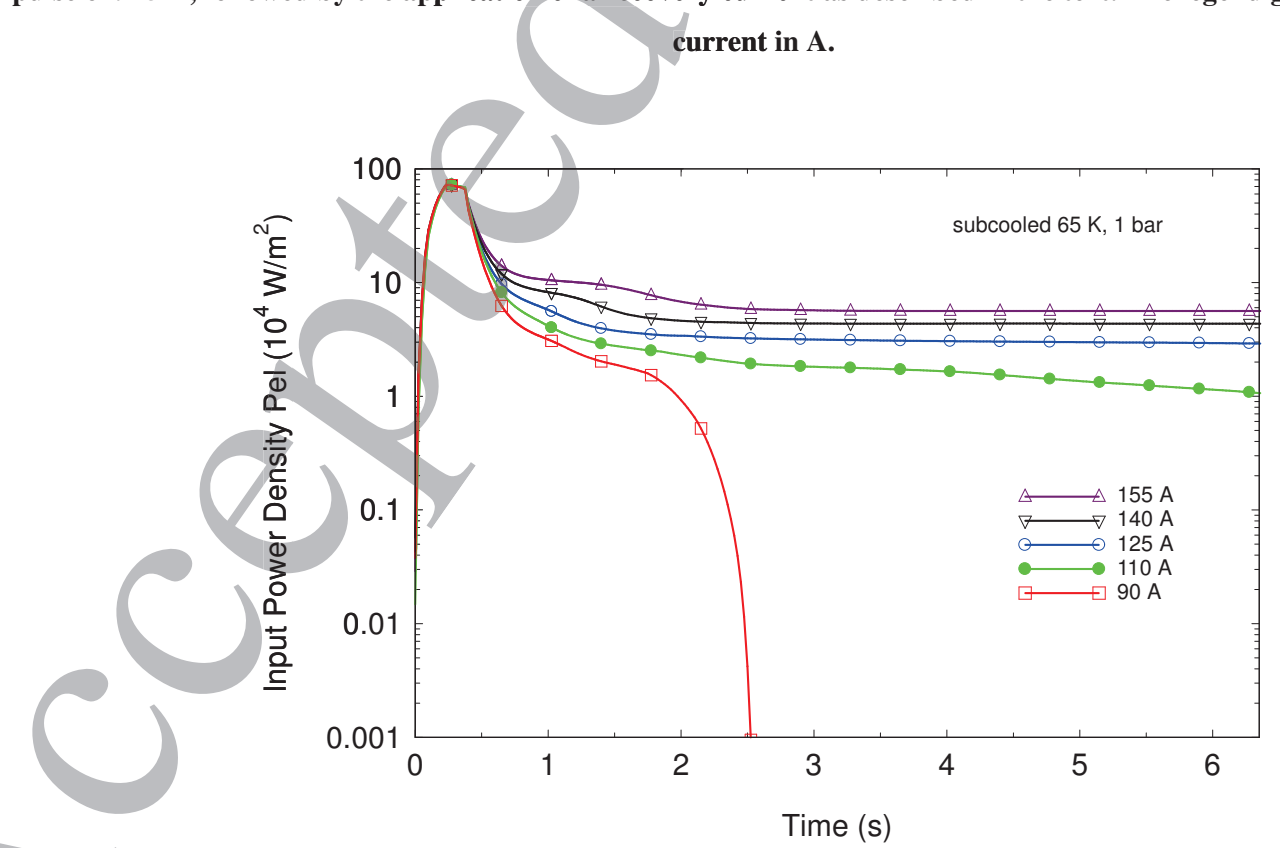

Figure 14. Input power density as a function of time for an HTS tape with $55 \mu \mathrm{m}$ PU coating during cool-down in subcooled LN2 at $65 \mathrm{~K}, 1$ bar, with recovery current flowing as indicated in the legend. 
Table 4. Heat transfer and recovery characteristics of superconducting tape with different thickness coatings in subcooled LN2 at $65 \mathrm{~K}$, 1 bar.

\begin{tabular}{|c|c|c|c|}
\hline Coating & $\begin{array}{c}\text { Nominal thickness of coating } \\
(\mu \mathrm{m})\end{array}$ & $\begin{array}{c}\text { Free recovery time from } 285 \mathrm{~K} \\
(\mathrm{~s})\end{array}$ & $\begin{array}{c}\text { Maximum heat transfer } \\
\left(\mathrm{W} / \mathrm{cm}^{2}\right)\end{array}$ \\
\hline None & 0 & 2.6 & 3.3 \\
\hline PU & 45 & 0.68 & 24.5 \\
\hline PU & 55 & 0.7 & 26.8 \\
\hline PU & 100 & 0.80 & 22.3 \\
\hline PU & 120 & 0.85 & 11.5 \\
\hline Kapton & 25 & 2.0 & \\
\hline
\end{tabular}

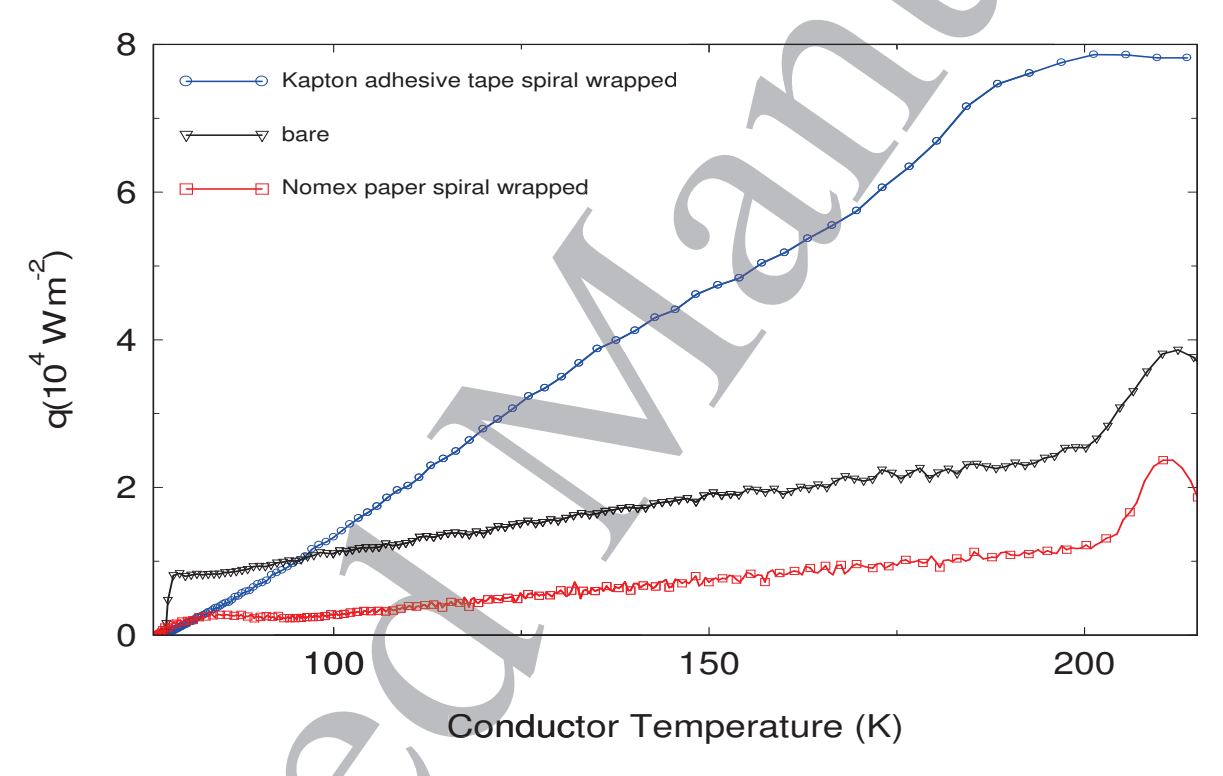

Figure 15. Heat transfer in cooling of copper tape in LN2 at 77K SVP: bare tape, with adhesive Kapton wrap, and nonadhesive Nomex paper wrap.

\subsection{Effect of wrapped insulation on heat transfer}

Wrapped kraft paper is a standard insulation material in conventional oil-immersed power transformers to obtain the insulation levels required for high voltage windings. Both kraft $\operatorname{paper}^{31}$ and aramid ${ }^{32}$ paper wrap have been proposed for HTS transformer insulation. In order to investigate the heat transfer characteristics of wrapped conductors, we prepared samples with Nomex paper and Kapton adhesive tape wrapped on $0.3 \mathrm{~mm}$ thick, $5 \mathrm{~mm}$ wide copper tape. The Nomex was type 401 paper, $0.05 \mathrm{~mm}$ thick, $10 \mathrm{~mm}$ in width, and the Kapton thickness was $25 \mu \mathrm{m}$. Both were wrapped around the copper wire with $25 \%$ lap under $3 \mathrm{~kg}$ tension.

Figure 15 shows heat transfer during cool-down of a $0.3 \mathrm{~mm}$ thick copper tape with different wrapped coating in LN2 at 77 K SVP. Heat transfer with the wrapped Nomex paper insulation is significantly reduced, to less than half that of the bare tape. This is most likely due to the LN2 in direct contact with the tape under the Nomex paper. We hypothesise that the LN2 evaporates during the heating pulse and establishes a gas sheath around the tape that is confined by the paper 
wrap and is therefore more stable than the gas film around a bare tape in the film boiling regime. The combination of vapour and paper wrap insulates the tape surface from contact with the LN2, so that the heat transfer is drastically reduced. In contrast, the wrapped Kapton adhesive tape prevents direct contact of the LN2 with the tape and allows heat transfer by nucleate boiling, increasing the heat transfer as much as $8 \mathrm{x}$ compared to the Nomex paper wrap.

\subsection{Effect of one-sided contact with an insulating former on heat transfer}

In conventional power transformers the relatively massive copper conductors are partially self-supporting and are typically held in place under tension using a range of pressboard spacers. In HTS power transformers applications, the HTS conductors, with their much smaller cross-section and vulnerability to damage by localised deformation, need to be immobilized by winding under tension on insulating formers or in multilayer pancake coils. Contact under tension with unyielding surfaces with small radius of curvature will damage the wire and must be avoided. Winding formers need to be robust, non-conductive, non-magnetic and ideally have thermal contraction matching that of the HTS tapes. They are usually made of G10 epoxy-glass composite material. In order to resist the large Lorentz forces on the conductors during short circuit or inrush current transients, HTS conductors, particularly high current conductors such as Roebel cables, have been immobilized by mounting them in trenches machined in composite formers ${ }^{29}$. The problem with this configuration is the reduced heat transfer because only one side of the HTS wire is exposed to the LN2 and the other side is held in tension against the G10 former. For this reason it is important to measure the effect of the insulating substrate/former on heat transfer. For this purpose, a $0.3 \mathrm{~mm}$ thick, $4.8 \mathrm{~mm}$ wide copper tape was mounted under $13 \mathrm{~kg}$ tension in a $1.5 \mathrm{~mm}$ deep, $5 \mathrm{~mm}$ wide trench machined circumferentially on outside of a G10 former, external diameter $138 \mathrm{~mm}$, as depicted in Figure 2.

Note that the power values are normalised here by the total surface area of the sample, not by the area of the exposed face of the sample. This means if contact with the substrate entirely eliminates heat transfer on the contact face, then the total surface heat transfer should be halved compared to the free-standing sample.

Plots of stable convective cooling heat transfer versus conductor temperature are shown in Figure 16(a) for both isolated and in-groove copper tape at different LN2 temperatures in subcooled and SVP conditions. In both SVP and subcooled conditions, the convective heat transfer and the maximum convective heat transfer achievable before the onset of boiling decrease when the conductor is mounted in the groove. In order to quantitatively estimate the reduction, the curves for both free-standing and in-groove conductors were fit, as for the data in Figure 5, with the power law Equation (2). The curves for in-groove heat convection are brought into good agreement with the curves for the free-standing sample using the scaling factors $q$ (in-groove) $/ q$ (free-standing) given in Table 5.

Table 5. Fit parameters for stable convective cooling heat transfer curve for conductors mounted in-groove; in a trench on a glass epoxy composite former.

\begin{tabular}{|c|c|c|c|c|c|}
\hline Fit Parameters for & T0 $(\mathrm{K})$ & $\mathrm{a}\left(\mathrm{W} /{\left.\mathrm{K} . \mathrm{cm}^{2}\right)}\right)$ & $\delta$ & Scaling Factor $(\%)$ & In-groove $\mathbf{q}_{\max }\left(\mathrm{W} / \mathrm{cm}^{2}\right)$ \\
\hline SVP 77K & 77.3 & 0.053 & 0.074 & 93.6 & 0.204 \\
\hline Subcooled 70K & 70.4 & 0.032 & 0.17 & 62.4 & 0.475 \\
\hline Subcooled 65K & 65.9 & 0.033 & 0.15 & 56.5 & 0.765 \\
\hline
\end{tabular}

For the conductor in subcooled LN2, the effect of mounting in the groove is to reduce the convective heat transfer almost by half, to around $62 \%$ and $57 \%$ for the $70 \mathrm{~K}$ and $65 \mathrm{~K}$ subcooled liquid respectively, rather than $50 \%$, so a minor 
contribution remains from the occluded face of the conductor. In contrast, the convective heat transfer from the conductor at SVP is barely reduced, by only about $6 \%$, by mounting in the trench. It may be that in SVP conditions some local boiling is taking place in the thin layer of liquid confined between the former and the conductor tape to augment the convective heat transfer from the exposed face of the tape.

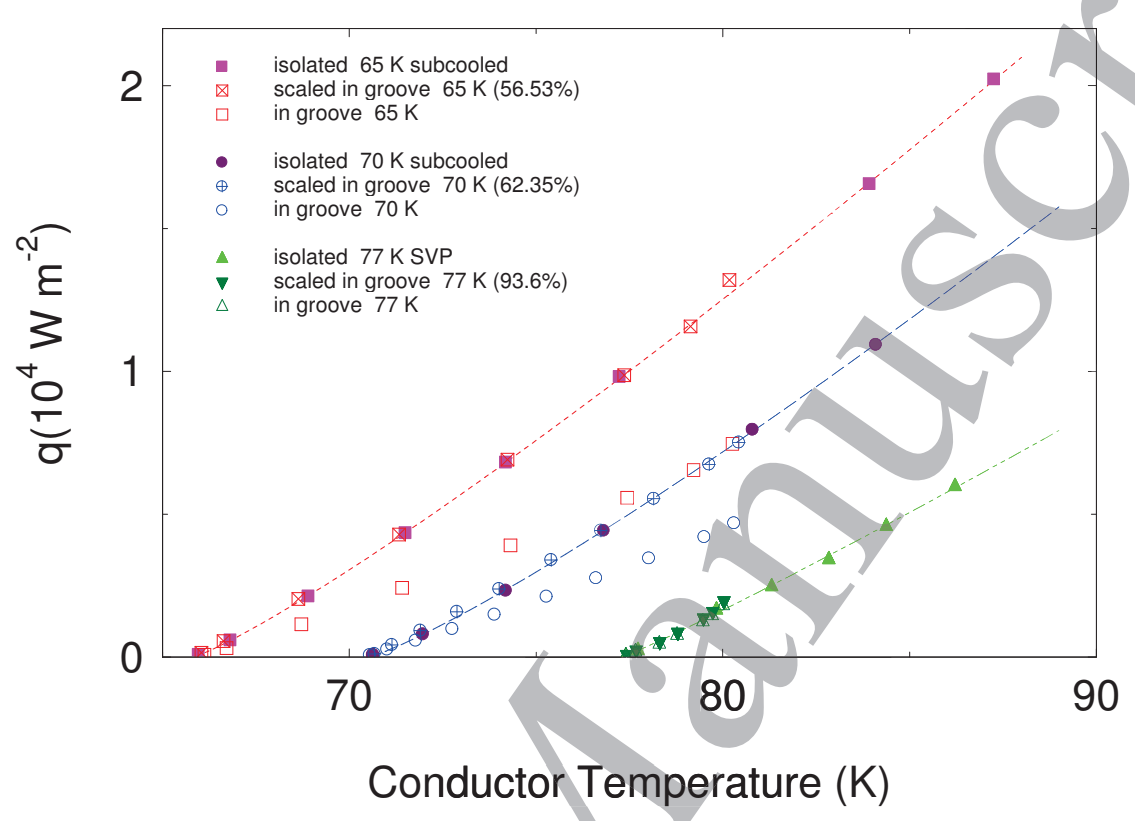

a. Stable natural convection curves

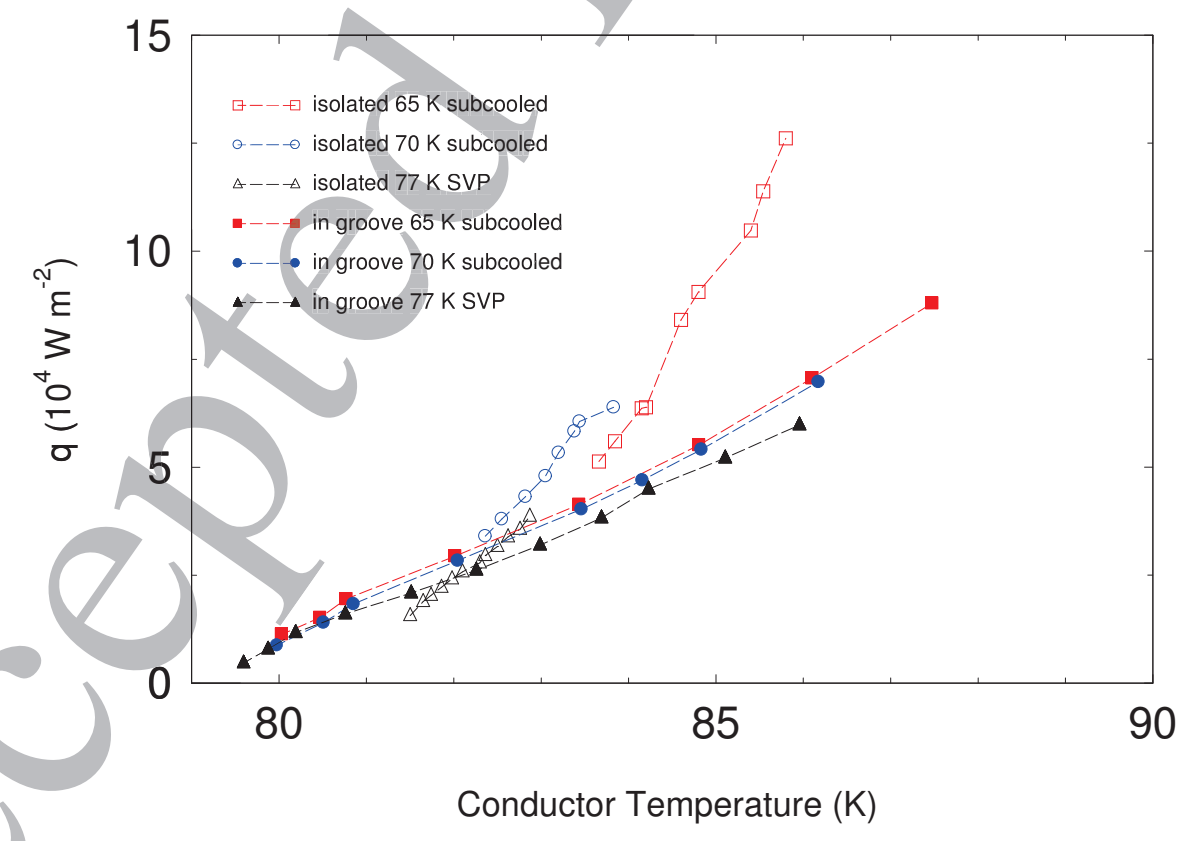

b. Stable nucleate boiling curves

Figure 16. Plots of (a) stable natural convection and (b) stable nucleate boiling heat transfer versus conductor temperature for $0.3 \mathrm{~mm}$ thick copper tapes mounted in a groove on an insulating substrate immersed in LN2 at SVP atmospheric pressure and subcooled situations compared to free-standing tapes 
Figure 16(b) shows the heat transfer for SNB as a function of conductor temperature for a $0.3 \mathrm{~mm}$ thick copper tape ingroove at different LN2 temperatures in the SVP and subcooled condition compared with a free-standing tape. The ingroove and free-standing curves seem to cross. It appears that the degree of superheating to initiate nucleate boiling has been reduced by contact with the composite former - the in-groove curves extrapolate back to close to $79 \mathrm{~K}$, while the free-standing curves appear to originate near $81 \mathrm{~K}$. This is perhaps to be expected since the contact zone between the conductor and former will provide a high density of potential nucleation sites for boiling.

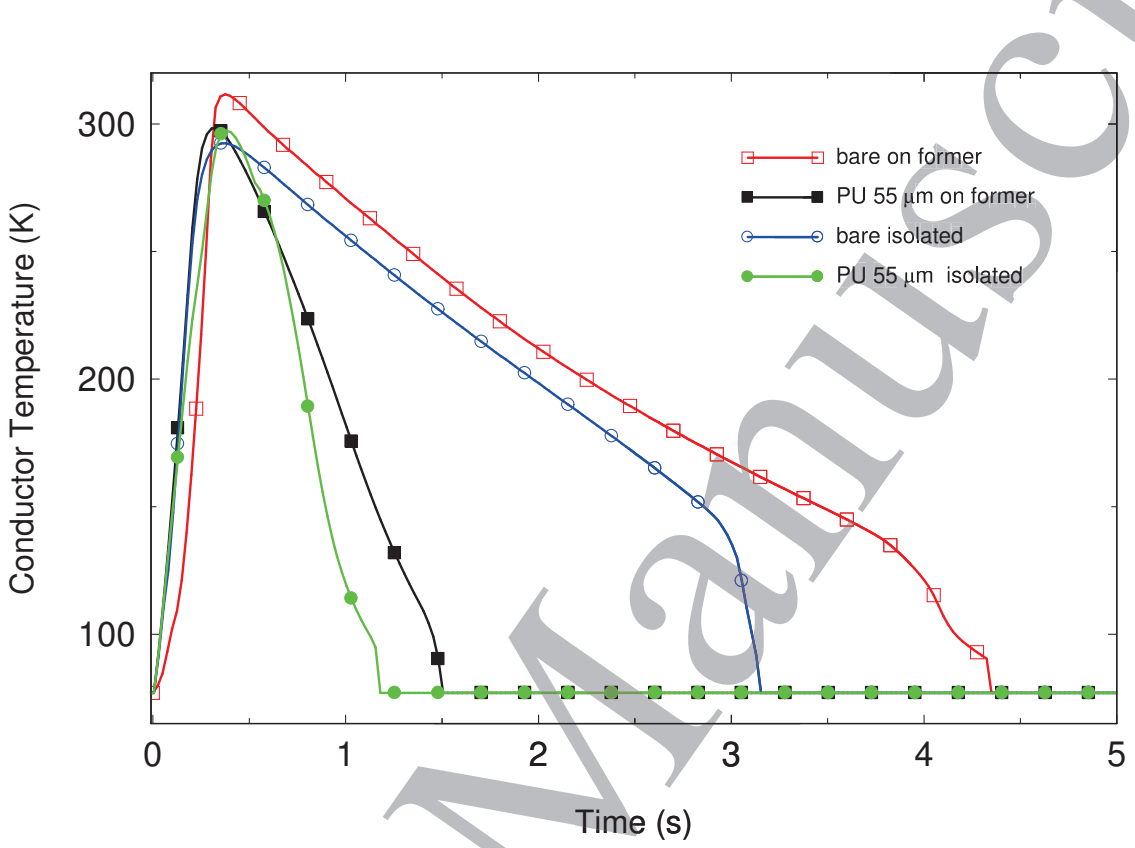

a. Conductor temperature versus time

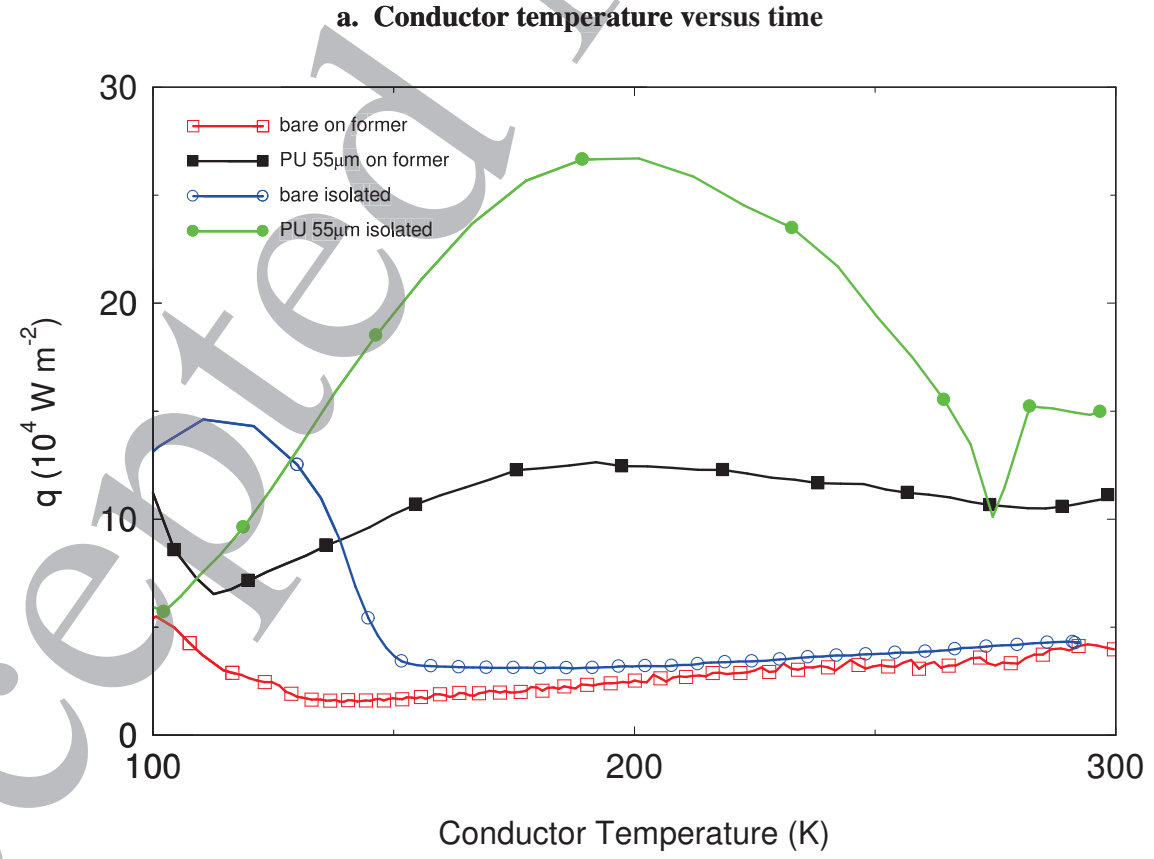

b. Heat transfer versus conductor temperature

Figure 17. HTS tape samples immersed in subcooled LN2 at $65 \mathrm{~K}$ during cool-down: comparison of bare tapes and with $55 \mu \mathrm{m}$ coating; free-standing, and mounted in-groove 
Cool-down from temperatures around $300 \mathrm{~K}$ was also measured for coated and bare HTS samples mounted in-groove on the composite former. Figure 17(a) compares the conductor temperature versus time for isolated and groove-mounted samples. Cool-down takes longer for in-groove samples, both bare and coated. Although the reduction in cool-down time does not seem great, the corresponding heat transfer curves, shown in Figure 17(b), reveal that the peak heat transfer for the coated tape is roughly halved by mounting on the former. For the bare tape, mounting on the former appears to almost eliminate the nucleate boiling peak, shifting it to lower temperatures around the superconducting transition temperature of the tape.

\section{Conclusions}

Heat transfer is of fundamental importance to HTS transformer technology. Efficient convective heat transfer is required to ensure that $\mathrm{AC}$ loss during normal operation does not raise the conductor temperature enough to significantly reduce the critical current. Boiling heat transfer is important for ensuring rapid cool-down after a fault current has raised the conductor temperature to $300 \mathrm{~K}$ or more, including recovery under load with current flowing in the metal stabiliser layers of the HTS conductor. In the case of extended fault current duration, up to $1 \mathrm{~s}$ or longer, heat transfer has an important role, along with the thermal mass of the conductor, in limiting the maximum conductor temperature and extending the fault withstand time.

In this paper we report measurements of heat transfer relevant to the design of HTS transformer windings. Our main findings are as follows:

- Importance of subcooling for improving heat transfer and recovery: Subcooling of LN2 significantly increases the boiling heat transfer compared to LN2 at SVP. Thus, sub-cooling is advantageous for HTS transformers not only for the improvement in critical current at lower temperatures and the avoidance of bubbles in normal operation, but also for improving heat transfer and recovery performance.

- Extended nucleate boiling: Conductors with a solid insulation coating with optimized thermal resistance exhibit extended nucleate boiling (ENB). They have much greater boiling heat transfer than bare conductors because the coating surface, insulated from the conductor, stays within the nucleate boiling regime and avoids the lower heat transfer associated with film boiling. The measured conductor temperature at peak nucleate boiling was shown to be consistent with the coating thickness and thermal conductivity of typical polymers in this temperature range. The convective heat transfer with ENB coatings with optimal thermal resistance in place is slightly reduced, by about $20 \%$, compared to bare surfaces.

- High level of heat transfer achieved by optimized solid coating: Compared with a bare HTS tape in 77 K LN2 at SVP, the recovery time and maximum heat transfer of a coated HTS sample with a PU coating $55 \mu \mathrm{m}$ thick in subcooled LN2 at $65 \mathrm{~K}, 1 \mathrm{bar}$, are 7x shorter and 15x higher respectively. The maximum heat transfer, measured at a conductor temperature close to $200 \mathrm{~K}$, was about $27 \mathrm{~W} / \mathrm{cm}^{2}$. Because of the enhanced heat transfer, the Type 8700 HTS tape, despite the relatively high resistance of its brass stabilizer, was able to cool down from around $300 \mathrm{~K}$ and regain the superconducting state while carrying a recovery current of close to $100 \mathrm{~A}$.

- Limitations of Nomex paper in HTS transformer applications: Conductor tapes with wrapped Nomex paper insulation have very significantly reduced boiling heat transfer compared to bare conductors. This suggests that, for HTS transformer windings, solid insulation should be preferred to the wrapped paper insulation typical of the oilimmersed windings of conventional transformers.

Effect of mounting on former/substrate: Heat transfer in subcooled LN2 is almost halved by mounting on an insulating substrate. This result suggests that the investigation of multi-layer winding configurations that do not unduly reduce the high boiling heat transfer demonstrated here for free-standing conductors should be a priority. 


\section{References}

${ }^{1}$ Power transformers-Part 5: Ability to withstand short circuit, IEC 60076-5 Standard, $3^{\text {rd }}$ edition, 2006.

${ }^{2}$ M. Noe, and M. Steurer, High-temperature superconductor fault current limiters: concepts, applications, and development status, Superconductor Science and Technology, vol. 20, no. 3, 2007.

${ }^{3}$ E. Pardo, M. Staines, Z. Jiang, and N. Glasson, AC loss modelling and measurement of superconducting transformers with coatedconductor Roebel-cable in low-voltage winding, Superconductor Science and Technology, vol. 28, no. 11, 2015.

${ }^{4}$ M. Kida, Y. Kikuchi, O. Takahashi, and I. Michiyoshi, Pool-Boiling Heat Transfer in Liquid Nitrogen, Journal of Nuclear Science and Technology, vol. 18, 1981, pp. 501-513.

${ }^{5}$ D. N. Sinha, L. C. Brodie, J. S. Semura, and F. M. Young, Premature transition to stable film boiling initiated by power transients in liquid nitrogen, Cryogenics, vol. 19, no. 4, 1979, pp. 225-230.

${ }^{6}$ V. Drach, N. Sack, and J. Fricke, Transient heat transfer from surfaces of defined roughness into liquid nitrogen, International Journal of Heat and Mass Transfer, vol. 39, no. 9, 1996, pp. 1953-1961.

${ }^{7}$ B. V. Balakin, M. I. Delov, K. V. Kutsenko, A. A. Lavrukhin, and O. V. Zhdaneev, Heat transfer from Ni-W tapes in liquid nitrogen at different orientations in the field of gravity, Cryogenics, vol. 65, 2015, pp. 5-9.

${ }^{8}$ S. Hellmann, and M. Noe, Influence of Different Surface Treatments on the Heat Flux from Solids to Liquid Nitrogen, IEEE Transactions on Applied Superconductivity, vol. 24, no.3, 2014, pp. 1-5.

${ }^{9}$ T. Rubeli, B. Dutoit, I. Martynova, A. Makarevich, A. Molodyk and S. Samoilenkov, Insulation effect on thermal stability of Coated Conductors wires in liquid nitrogen, IOP Conference Series: Materials Science and Engineering, vol. 171, 2017, pp. 1-8.

${ }^{10}$ C. W. Cowley, W. J. Timson, and J. A. Sawdye, A method for improving heat transfer to a cryogenic fluid, Advances in Cryogenic Engineering, vol. 7, 1962, pp. 385-39.

${ }^{11}$ W. J. Timson, Boiling heat transfer system, March 18 1969, US Patent 3,433,294.

${ }^{12}$ A. Berger, M. Noe, and A. Kudymow, Recovery Characteristic of Coated Conductors for Superconducting Fault Current Limiters, IEEE Transactions on Applied Superconductivity, vol. 21, no. 3, 2011, pp. 1315-1318.

${ }^{13}$ N. Glasson, M. Staines, R. Badcock, L. Ward, N. Allpress, K. Thakur, and M. Pannu, Risk mitigation in the development of a Roebel cable based 1 MVA HTS transformer, Physics Procedia, vol. 36, 2012, pp. 830-834.

${ }^{14}$ P. Wang, P. L. Lewin, D. J. Swaffield, and G. Chen, Electric field effects on boiling heat transfer of liquid nitrogen, Cryogenics, vol. 49, 2009, pp. 379-389.

${ }^{15}$ J. W. Lue, M. J. Gouge, and R. C. Duckworth, Over-eurrent testing of HTS tapes, IEEE Transactions on Applied Superconductivity, vol. 15 , no. 2, 2005, pp. 1835-1838.

${ }^{16}$ A. Ishiyama, Y. Tanaka, H. Ueda, Y. Shiohara, T. Machi, Y. Iijima, T. Saitoh, N. Kashima, M. Mori, T. Watanabe, and S. Nagaya, Degradation of YBCO Coated Conductors Due to Over-Current Pulse, IEEE Transactions on Applied Superconductivity, vol. 17, no. 2, 2007, pp. 3509-3512.

${ }^{17}$ X. Wang, U. P. Trociewitz, and J. Schwartz, Critical current degradation of short YBa2Cu3O7- $\delta$ coated conductor due to an unprotected quench, Superconductor Science and Technology, vol. 24, no. 3, 2011.

${ }^{18}$ M. Yazdani-Asrami, M. Staines, G. Sidơrov, M. Davies, J. Bailey, N. Allpress, N. Glasson, and S. Asghar Gholamian, Fault current limiting HTS transformer with extended fault withstand time, Supercond. Sci. Technol. vol. 32, no.3, 2019, 035006

19 S. Nukiyama, Maximum and minimum values of heat transmitted from metal to boiling water under atmospheric pressure, Transactions of the Japan Society of Mechanical Engineers, vol. 37, 1934, pp. 367-374.

${ }^{20}$ S. Hellmann, and M. Noe, Optical and Electrical Investigation of a Novel Method for Improving the Recovery under Load Characteristics of Thin Film Superconductors, In the proceedings of the $12^{\text {th }}$ European Conference on Applied Superconductivity (EUCAS 2015), 2015, 3M-LS-O2.

${ }^{21}$ P. D. Desai, Thermodynamic properties of nickel, International Journal of Thermophysics, vol. 8, 1987, pp. 763-780.

${ }^{22}$ Data for copper and brass, NIST cryogenic material database, https://trc.nist.gov/cryogenics/materials/materialproperties.htm

${ }^{23}$ R. A. Matula, Electrical resistivity of copper, gold, palladium, and silver, Journal of Physical and Chemical, Reference Data 8, 1979, pp. 1147. 
${ }^{24}$ C. Y. Ho, M. W. Ackerman, K. Y. Wu, T. N. Havill, R. H. Bogaard, R. A. Matula, S. G. Oh, and H. M. James, Electrical Resistivity of Ten Selected Binary Alloy Systems, Journal of Physical and Chemical, Reference Data 12, 1983, pp. 183-322

${ }^{25}$ P. N. Degtyarenko, I. N. Dul'kin, L. M. Fisher, G. I. Garas'ko, A. V. Kalinov, S. B. Vavilov, and I. F. Voloshin, Temperature Rise of Copper and HTSC Tapes in Liquid Nitrogen by a Step-wise Current Pulse, Physics Procedia, vol. 36, 2012, pp. 596-599.

${ }^{26}$ V. S. Nikolayev, and D. A. Beysens, Boiling crisis and non-equilibrium drying transition, Europhysics Letters, vol. 47, no. 3, 1999, pp. 345-351.

${ }^{27}$ R. Span, E. W. Lemmon, R. T. Jacobsen, W. Wagner, and A. Yokozeki, A Reference Equation of State for the Thermodynamic Properties of Nitrogen for Temperatures from 63.151 to $1000 \mathrm{~K}$ and Pressures to $2200 \mathrm{MPa}$, Journal of Physical and Chemical Reference Data 29, 2000, pp. 1361-1433

${ }^{28}$ R. F. Barron, and G. F. Nellis, Cryogenic Heat Transfer, $2^{\text {nd }}$ Edition, CRC Press, 2016.

${ }^{29}$ M. Staines, N. Glasson, M. Pannu, K. P. Thakur, R. Badcock, N. Allpress, P. D'Souza, and E. Talantsev, The development of a Roebel cable based 1 MVA HTS transformer, Superconductor Science and Technology, vol. 25, no. 1, 2012, pp. 1-7.

${ }^{30}$ C. L. Choy, Thermal conductivity of polymers, Polymer, vol. 18, 1977, pp. 984-1004.

${ }^{31}$ E. F. Pleva, V. Mehrotra, and S. W. Schwenterly, Conductor requirements for high-temperature superconducting utility power transformers, Superconductor Science and Technology, vol. 23, no.1, 2010, pp. 1-5.

${ }^{32}$ M. O'Neill, W. G. Enright, and P. S. Bodger, Electro-mechanical Testing of a Liquid Nitrogen Filled Power Transformer, In Proceedings of the $13^{\text {th }}$ Conference of the Electric Power Supply Industry (CEPSI 2000), 2000. 